\title{
Predicting the Resistance Profile of a Spudcan Penetrating Sand Overlying Clay
}

Manuscript submitted to Canadian Geotechnical Journal on 03/10/2013

Revised manuscript submitted on 12/03/2014

Manuscript accepted on 23/04/2014

\section{Pan Hu}

Centre for Offshore Foundation Systems, the University of Western Australia 35 Stirling Highway, Crawley, WA6009, Australia

Email: 20848369@ student.uwa.edu.au

\section{Dong Wang (corresponding author)}

Centre for Offshore Foundation Systems, the University of Western Australia 35 Stirling Highway, Crawley, WA6009, Australia

Tel: +61864883447

Fax: +61 864881044

Email: dong.wang@uwa.edu.au

\section{Mark J. Cassidy}

Centre for Offshore Foundation Systems, the University of Western Australia 35 Stirling Highway, Crawley, WA6009, Australia

Email: mark.cassidy@uwa.edu.au

\section{Sam A. Stanier}

Centre for Offshore Foundation Systems, the University of Western Australia 35 Stirling Highway, Crawley, WA6009, Australia

Email: sam.stanier@uwa.edu.au 


\begin{abstract}
Assessment of the risk of punch-through failure of spudcan foundations on sand overlying clay requires prediction of the full penetration-resistance profile, from touchdown and through punchthrough to equilibrium of the vertical resistance at depth in the underlying clay layer. This study uses the Coupled Eulerian-Lagrangian approach, a large deformation finite element analysis method, to model the complete penetration resistance profile of a spudcan on sand overlying clay. The sand is modeled using the Mohr-Coulomb model, while the clay is modeled using a modified Tresca model to account for strain softening. The numerical method is then used to simulate a series of spudcan penetration tests, performed in a geotechnical centrifuge, on medium dense sand overlying clay. The punch-through behavior observed in the experiments is replicated, and the penetration resistance profiles from numerical analyses are generally a reasonable match to the experimental measurements. The influences of the sand layer height to foundation diameter ratio, sand-clay interface shear strength and strength gradient in clay on the penetration resistance profiles are explored in a complementary parametric study. The penetration resistance in the underlying clay layer is well predicted using a simple linear expression for the bearing capacity factor for the spudcan and underlying sand plug. This expression is combined with an existing failure stressdependent model for predicting peak resistance to form a simplified method for prediction of the full penetration resistance profile. This new method provides estimates of the vertical penetration that the spudcan will run during the punch-through event. It is validated against both medium dense and dense sand centrifuge tests.
\end{abstract}

\title{
Keywords
}

Spudcan; Sand; Clay; Punch-through; Centrifuge modeling; Finite element method 


\section{Introduction}

Unexpectedly sudden and rapid penetrations of spudcan foundations during installation are a major risk to the stability of jack-up platforms. This can occur when under vertical loading the large (often $\sim 20 \mathrm{~m}$ diameter) spudcan pushes a layer of strong sandy material into an underlying weak clay layer. Rapid spudcan and leg penetration occurs until the applied jack-up weight (and preloading ballast weight) equates with the resistance in the underlying clay layer. If not handled properly, the large displacement of the leg may cause damage to the structure of the jack-up or down-time. This type of event is termed a punch-through failure.

To assess the risk of punch-through during the installation of jack-up rigs, an accurate prediction of the spudcan penetration resistance profile is thus critical. Two 'wished-in-place' methods are recommended by the ISO (2012) guidelines to estimate the peak penetration resistance of a spudcan in layered strata where punch-through might be a possibility. In both methods the bearing capacity is calculated at a specified penetration depth, assuming a pre-embedded spudcan and undisturbed soil stratigraphy and strengths. When used to back-calculate centrifuge data, the ISO (2012) prediction methods significantly underestimate the potential for punch-through ( $\mathrm{Hu}$ et al. 2014). There are currently no guidelines for the calculation of the bearing capacity following punchthrough into the underlying clay layer that account for the combined bearing capacity of the spudcan and any sand trapped beneath, as observed by Teh et al. (2008) using particle image velocimetry (PIV) analysis.

Simple methods are needed to predict the full penetration resistance profile for a spudcan penetrating through sand overlying clay that can be used routinely in site-specific assessment of jack-up safety (Osborne et al. 2006). Such methods should account for the mechanistic changes that occur at different stages of penetration, as observed by Teh et al. (2008). For simplicity, two key events might be used to define the severity of a punch-through event: (i) the magnitude and depth of peak resistance in the sand layer and (ii) the depth at which the resistance in the underlying clay layer becomes equal to the peak resistance. The depth between these two events is thus an estimate of the plunge depth that may be experienced in the field during preloading and can be used to check against serviceability limits for the jack-up platform. For the measurement of plunge depth from the testing profile, a tangent line from the depth at which the spigot is fully embedded following the penetration resistance profile towards peak resistance is constructed, followed by a vertical line to the equilibrium depth in the clay layer (where the current resistance is equal to the peak resistance in sand). The depth of the punch-through event, $d_{\text {punch }}$, is the length of the line from the depth of peak resistance until vertical equilibrium is re-established. 
The magnitude and depth of the peak resistance in the sand layer is readily calculable using the failure stress-dependent method derived by Lee et al. (2013b) for dense sand overlying clay. This model assumes that an inverted and truncated cone of sand is pushed down into the underlying clay, mobilizing shearing around the periphery of the inverted truncated cone and clay-bearing capacity at the base. Stress-dependent dilatancy is incorporated into the model using a modified form of Bolton's correlations by relating the dilatancy to the bearing pressure at failure (Bolton, 1986). The form of this model was enhanced by $\mathrm{Hu}$ et al. (2014) to account for mobilization embedment depth and further validated experimentally for medium dense to dense sand states.

Calculating the bearing capacity in the underlying clay is complicated by sand trapped underneath the spudcan. The bearing capacity of a spudcan in clay is commonly expressed as

$$
\mathrm{q}_{\text {clay }}=\mathrm{N}_{\mathrm{c}} \mathrm{s}_{\mathrm{u} 0}+\frac{\mathrm{V}_{\mathrm{f}} \gamma_{\mathrm{c}}^{\prime}}{\mathrm{A}}
$$

where $\mathrm{N}_{\mathrm{c}}$ is the bearing capacity factor; $\mathrm{s}_{\mathrm{u} 0}$ is the intact soil strength at the lowest elevation of the spudcan widest cross-sectional area (termed Load Reference Point, LRP); $V_{\mathrm{f}}$ is the embedded foundation volume below the spudcan LRP; $\gamma_{c}^{\prime}$ is the effective unit weight of the clay and A is the nominal surface area of the foundation $\left(\mathrm{A}=\pi \mathrm{D}^{2} / 4\right.$ and $\mathrm{D}$ is the diameter of the spudcan). The first term is the bearing capacity for a weightless soil, while the second term accounts for buoyancy. Following punch-through on sand overlying clay, the bearing capacity factor $\mathrm{N}_{\mathrm{c}}$ and volume of the foundation $\mathrm{V}_{\mathrm{f}}$ should be related to the composite geometry of the foundation and the trapped sand plug. However, application of Eq. 1 is difficult for this scenario due to uncertainty about the trapped sand plug volume and geometry. For example, Teh et al. (2008) observed using PIV analyses that the upper portion of the trapped sand beneath the spudcan resembled a cylinder with diameter similar to the spudcan, whereas the shape of the lower part was slightly irregular due to the metastable state of the trapped sand. In the experiments of Teh et al. (2008), the trapped sand plug height, $\mathrm{H}_{\text {plug }}$, was $\sim 1 \mathrm{H}_{\mathrm{s}}$, where $\mathrm{H}_{\mathrm{s}}$ is the height of the sand layer. Lee (2009) performed a series of small strain numerical analyses that assumed that the spudcan and sand plug could be idealized as a composite cylindrical foundation. Expressions for $\mathrm{N}_{\mathrm{c}}$ were related to the assumed composite foundation height and diameter, facilitating prediction of the full penetration resistance profile from a measured soil shear strength profile. In contrast to Teh et al. (2008), Lee (2009) found that a range of $\mathrm{H}_{\text {plug }}$ of 0.6 to $0.9 \mathrm{H}_{\mathrm{s}}$ was required to attain a good fit to the experimental measurements. Such uncertainty limits confidence in the application of Eq. 1 and further verification is necessary. An alternative approach is to back-calculate the bearing capacity factors from the experimental measurements of full spudcan load-penetration tests, as performed by Lee et al. (2013a), resulting in 


$$
\mathrm{N}_{\mathrm{c}}=14 \frac{\mathrm{H}_{\mathrm{s}}}{\mathrm{D}}+9.5 \quad\left(0.21 \leq \frac{\mathrm{H}_{\mathrm{s}}}{\mathrm{D}} \leq 1.12\right)
$$

The full penetration resistance profile can also be predicted using large deformation finite element methods. These methods require no prior assumption of the failure mechanisms and may be in conjunction with advanced constitutive models to attempt to faithfully replicate soil behavior. Compared with traditional Lagrangian finite element methods, large deformation analysis avoids severe mesh distortion. Two such methods have been used to replicate the continuous penetration process of a spudcan on sand overlying clay:

(i) The Remeshing and Interpolation Technique with Small Strain (RITSS) method was used by Yu et al. (2012) to investigate the effects of the undrained shear strength of the underlying clay and the thickness and friction angle of the upper sand. A simple equation was proposed to relate the postpeak bearing capacity factor to the soil properties in which the bearing capacity factor is directly related to the strength ratio between the sand and the clay

$$
\mathrm{N}_{\mathrm{c}}=3.3\left(\frac{\mathrm{H}_{\mathrm{s}} \gamma_{\mathrm{s}}^{\prime} \tan \phi^{\prime}}{\mathrm{s}_{\mathrm{u} 0}}\right)+12
$$

where $\gamma_{s}^{\prime}$ and $\phi^{\prime}$ are the effective unit weight and internal friction angle of sand, respectively. However, this equation is summarized based on a limited numerical study and does not account for the increase of $\mathrm{N}_{\mathrm{c}}$ with $\mathrm{H}_{\mathrm{s}} / \mathrm{D}$ observed experimentally by Lee et al. (2013a).

(ii) The Coupled Eulerian-Lagrangian (CEL) approach that is available in the commercial package ABAQUS/Explicit. The CEL approach was first adopted for research of spudcan performance by Tho et al. $(2009,2012)$ to compare numerical penetration resistances and soil flow mechanisms with centrifuge results. Qiu and Henke (2011) and Qiu and Grable (2012) later incorporated hypoplastic and visco-hypoplastic constitutive models into the CEL approach to better simulate the complex rate and strain-hardening-softening dependent behaviors of sand and clay. No recommendations on the bearing capacity factor for the composite spudcan and sand plug in the underlying clay were provided in previous CEL studies.

In this paper, the CEL approach is used to simulate continuous spudcan penetration on loose and medium dense sand overlying clay with increasing shear strength with depth, while accounting for strain softening in the clay layer. The numerical methods are first validated by comparison with previous numerical and centrifuge test data for spudcan penetration in normally consolidated clay and in uniform sand. The impacts of mesh density, penetration rate, foundation interface friction and clay softening are then considered. The CEL analyses are conducted to simulate a series of centrifuge tests performed on medium dense sand overlying clay alongside a parametric study that 
broadens the scope to cover the geometric conditions relevant to spudcan punch-through in the field. Sand plug heights and bearing capacity factors in the clay layer are then inferred from the CEL analyses and are shown to be a good fit for a simple linear relationship. These simple equations can be used to predict the bearing capacity profile in the lower clay layer and, when coupled with the failure stress-dependent model by $\mathrm{Hu}$ et al. (2014), to derive an estimate for the depth of a punchthrough event. The performance of the simplified prediction method is verified against experimental centrifuge data for medium dense to dense sand overlying clay.

\section{Numerical methodology}

\subsection{Implementation of CEL approach}

In the CEL approach, the spudcan and soil are discretized using Lagrangian and Eulerian mesh respectively. The Eulerian mesh is composed of 8-node linear hexahedron elements with reduced integration and hourglass control. The soil materials are allowed to flow through Eulerian elements whose nodes have fixed locations (Dassault Systèmes, 2011). The Eulerian mesh is initially composed of two parts, one that is initially occupied by soil and another that is void to accommodate any soil heave created during the penetration process. An Eulerian element may be partially void or filled with multiple materials. The presence and volume fractions of different materials in each Eulerian element are specified at the beginning of the analysis. In contrast, only one material is contained in a Lagrangian element. During the analysis, the Eulerian material is tracked as it flows through the mesh by computing its volume fraction within each element.

Each incremental step in a CEL analysis consists of two phases, Lagrangian and Eulerian. An updated Lagrangian calculation is conducted in an explicit integration scheme, followed by an Eulerian phase in which advection is performed to map the solution variables (such as material properties, stresses, strains, velocities and accelerations) from the deformed mesh to the original mesh. The Eulerian material boundaries and interfaces are updated through the volume fractions of each material and generally do not correspond to element boundaries.

The contact interactions between different Eulerian materials (sand and clay) were not defined because the materials deform continuously, and there is no slip between them. The interaction between the Eulerian materials (soils) and the Lagrangian material (spudcan) was described with a 'general contact' algorithm that is based on frictional contact using the penalty method. Rather than the traditional small-sliding frictional formulation, a finite-sliding formulation was implemented to consider arbitrary slide on the interface in large deformation problems. During spudcan penetration into sand overlying clay, contact between the spudcan and sand will be maintained during the entire 
penetration process. Frictional interaction between the spudcan and sand was defined through a roughness factor (Cassidy and Houlsby, 2002)

$$
\alpha=\frac{\tan \delta}{\tan \phi^{\prime}}
$$

where $\delta$ is the interface friction angle between sand and spudcan.

The current CEL approach in ABAQUS/Explicit has only three-dimensional elements. By taking advantage of geometrical symmetry, only one quarter of the spudcan and soil were modeled. The geostatic stresses due to the submerged unit weight of the soil were imposed before spudcan penetration, with a coefficient of lateral earth pressure of $\left(1-\sin \phi^{\prime}\right)$ for the sand layer and unity for the clay layer.

To enhance solution accuracy, the soil region in contact with the spudcan must be refined. The penetration of a spudcan was simulated with displacement-control. In contrast, spudcan penetration in the field is a load-controlled quasi-static process; hence, the penetration rate adopted in the CEL simulations, which is based on an explicit integration scheme, needs to be sufficiently low to avoid inertial effects. In the penetration resistance profiles presented herein, the depth of penetration, d, was zero when the LRP contacts the soil.

\subsection{Constitutive models}

The spudcan penetration rates in practical offshore applications are on the order of $(1-3) \mathrm{m} / \mathrm{h}$. Penetration rates in centrifuge model tests are usually selected such that drained deformation occurs in the upper sand layer, while undrained response occurs in the clay layer (Teh et al. 2010; Lee et al. 2013a; Hu et al. 2014). This arrangement is achieved by specifying that the normalized velocity $\mathrm{vD} / \mathrm{c}_{\mathrm{v}}$ (where $\mathrm{v}$ is the absolute penetration rate and $\mathrm{c}_{\mathrm{v}}$ is the coefficient of consolidation) is in the range of $30-300$ for the clay layer and less than 0.01 for the sand layer (Finnie and Randolph, 1994; Low et al. 2008; Cassidy, 2012).

Loose to medium dense sand usually shows a hardening rather than softening response under drained conditions, so the sand layer was modeled as an elastic-perfectly plastic material with a Mohr-Coulomb yield criterion. The internal frictional angle was specified as the critical value, unless otherwise stated, because (i) the primary aim is to model the deep penetration resistance in the clay layer following punch-through; (ii) the sand beneath the advancing spudcan undergoes extremely large deformation and (iii) has been shown by Li et al. (2013) to reach the critical state during deep penetration (in the clay layer). The sand volume is stable at the critical state; therefore, the dilation angle was $\psi=0$. 
The clay layer under undrained conditions was modeled as an elastic-perfectly plastic material with the Tresca yield criterion. The Poisson's ratio was 0.49 to approximate constant volume under undrained conditions. Because soil rigidity only slightly affects the penetration resistance, a typical Young's modulus of $500 \mathrm{~s}_{\mathrm{u}}$ was used throughout, where $\mathrm{s}_{\mathrm{u}}$ is the current undrained shear strength of the clay considering softening. The effect of strain softening is incorporated following Einav and Randolph (2005) by modifying the shear strengths at the integration points according to the accumulated absolute plastic shear strain

$$
\mathrm{s}_{\mathrm{u}}=\left[\delta_{\mathrm{rem}}+\left(1-\delta_{\text {rem }}\right) \mathrm{e}^{-3 \xi / \xi_{95}}\right] \mathrm{s}_{\mathrm{ui}}
$$

where $\mathrm{s}_{\mathrm{ui}}$ is the intact undrained shear strength; $\delta_{\text {rem }}$ denotes the ratio of fully remolded and initial shear strengths (the inverse of the sensitivity, $S_{t}$ ); $\xi$ is the accumulated absolute plastic shear strain; $\xi_{95}$ represents the value of $\xi$ required for the soil to undergo $95 \%$ remolding, estimated in the range of 10 to 50 for marine clays. In CEL implementations, the plastic shear strain increments in the clay layer were recorded to update the soil strength at the integration point through Eq. 5, and the updated strength was approximated as constant during the calculations of the subsequent step.

The chosen shear strength profile was based on that measured in the centrifuge tests. The intact undrained strength profile was measured using a T-bar penetrometer and was found to increase linearly with soil depth

$$
\mathrm{s}_{\mathrm{ui}}=\mathrm{s}_{\mathrm{um}}+\mathrm{kz}
$$

where $s_{u m}$ is the clay strength at mudline for a single clay layer or at the sand-clay interface for sand overlying clay; $\mathrm{k}$ is the strength gradient and $\mathrm{z}$ represents the soil depth. Hossain and Randolph (2009) found that the average shear strain rates induced in soils by spudcan and T-bar penetrometers were comparable; hence, it was unnecessary to consider the potential for shear strength enhancement due to rate effects.

\section{Verification of the CEL approach}

\subsection{Spudcan penetration in a single clay layer}

The bearing capacity factor of spudcan in normally consolidated clay has been investigated using different analytical and numerical approaches. A spudcan with diameter of $14 \mathrm{~m}$ penetrating in normally consolidated clay was studied by Mehryar and $\mathrm{Hu}$ (2002) using the RITSS approach. Detailed spudcan dimensions can be found in Fig. 1 in Mehryar and $\mathrm{Hu}$ (2002). The submerged unit weight of clay, $\gamma_{c}^{\prime}$, was $7 \mathrm{kN} / \mathrm{m}^{3}$, the undrained shear strength $\mathrm{s}_{\mathrm{ui}}=2 \mathrm{z} \mathrm{kPa}$ and no strain softening was considered. A CEL simulation was performed for comparison, with penetration rate $0.25 \mathrm{~m} / \mathrm{s}$, which was sufficiently slow to generate a quasi-static response. The typical element size around the 
spudcan was $0.036 \mathrm{D}$. The bearing capacity factors from the CEL, RITSS, traditional small strain FE and plasticity limit analyses are presented in Fig. 1(a). In the latter two analyses, the spudcan was assumed to be pre-embedded at different depths because the continuous penetration process cannot be tracked. As $\mathrm{d} / \mathrm{D}>0.5$, the bearing capacity factor predicted by the CEL is slightly higher than that predicted by the RITSS method, however, the bearing capacity factors from both approaches converge to $\sim 11$ at d/D of 3. The bearing capacity factors obtained from both LDFE approaches are moderately lower than that of the wished-in-place spudcans; the bearing capacity is overestimated if the drag-down of weaker soil indicated in Fig. 1(b) is ignored. The soil radially within $\sim 1 \mathrm{D}$ of the centerline of the spudcan is significantly disturbed by the penetration process.

\subsection{Spudcan penetration in a single sand layer}

White et al. (2008) reported a centrifuge test of a conical footing (very similar to a spudcan) with diameter of $4.8 \mathrm{~m}$ on medium dense sand (relative density $\mathrm{I}_{\mathrm{D}}=54 \%$ ). A CEL simulation was performed, assuming a Poisson's ratio of 0.3 and Young's modulus of $50 \mathrm{MPa}$. A constant $\mathrm{m}$ in correlations by Bolton (1986) was fitted by back-calculation as 0.85 by White et al. (2008), while $\mathrm{m}$ is typically 3 for a triaxial stress state. Corresponding operative friction angles calculated using Bolton's correlations were $33.22^{\circ}$ and $36.32^{\circ}$ for these two scenarios, so an average value of $34.8^{\circ}$ was assumed in the current analysis, along with a dilation angle of $\psi=4.8^{\circ}$ that was similarly based on Bolton's correlations. A friction coefficient of $\alpha=0.5$ on the spudcan-sand interface was adopted (the influence of which will be discussed in Section 4.2). The penetration rate was $0.1 \mathrm{~m} / \mathrm{s}$, and the element size around the spudcan was $\sim 0.03 \mathrm{D}$. The footing geometry in the CEL analysis was identical to the model used in the centrifuge tests.

As shown in Fig. 2, the numerical bearing capacity shows a trend similar to the experimental data with a maximum difference of $\sim 20 \%$. The difference may be due to the constant soil properties assumed in the CEL simulation. During the very early stages of penetration, the friction angle of the sand in reality is likely to be moderately higher than the value used in the CEL analyses because the friction angle in the numerical analyses did not vary with mean stress level. The friction angle may reduce gradually to a nearly constant value with increasing capacity during further penetration, which is consistent with the behavior modeled in the CEL analysis. For the spudcan penetration in loose or medium dense sand overlying clay, the simple and robust Mohr-Coulomb model was deemed adequate, as the primary concern was capturing the volume, geometry and bearing capacity characteristics in the clay layer of the composite foundation comprising the spudcan and sand plug. The periphery of the sand plug is expected to be subjected to large shear strains during penetration and thus will likely be at the critical state. Therefore, adoption of the Mohr-Coulomb model with a friction angle equal to the critical value is considered appropriate. 


\section{Simulation of centrifuge tests of medium dense sand overlying clay}

The penetration of a spudcan in medium dense sand overlying clay (see nomenclature in Fig. 3) behaves differently from that in a single clay or sand layer. CEL simulations were performed to replicate a total of 15 centrifuge tests (relative density $I_{D}=43 \%$ ) by $\mathrm{Hu}$ et al. (2014). The spudcan model of the centrifuge tests (Fig. 4), with a $13^{\circ}$ shallow conical underside profile and $76^{\circ}$ protruding spigot, was simulated for direct comparison with the experiments. The spudcan diameters and soil properties of each test are listed in Table 1. The Poisson's ratio and Young's modulus of sand were assumed to be 0.3 and $25 \mathrm{MPa}$, respectively. The critical state friction angle was $31^{\circ}$ for the super fine sand used in the centrifuge test (White et al. 2008). The sensitivity of the underlying kaolin clay, $\mathrm{S}_{\mathrm{t}}$, was 3 , based on cyclic T-bar measurements.

A typical test, L1SP1, with D of $6 \mathrm{~m}$ and normalized sand thickness $\mathrm{H}_{\mathrm{s}} / \mathrm{D}$ of 1 , was used as an example to demonstrate the mesh convergence, penetration rate for quasi-static simulation and effects of spudcan roughness and sensitivity of clay on penetration resistance.

\subsection{Mesh convergence and penetration rate}

Mesh convergence studies were conducted to ensure that the Eulerian mesh was sufficiently fine to avoid overestimation of the penetration resistance. Four typical element sizes, indicated as a ratio of the spudcan diameter, were adopted close to the spudcan: $0.018 \mathrm{D}, 0.025 \mathrm{D}, 0.03 \mathrm{D}$ and $0.05 \mathrm{D}$. The meshes had corresponding numbers of soil elements of 490821, 220031, 142560 and 49197, respectively. In order to minimize the computational cost, only a quarter of the domain was modeled. The mesh with element size of 0.025D was shown in Fig. 5. The spudcan was displaced at a penetration rate of $0.2 \mathrm{~m} / \mathrm{s}$. The penetration resistance profiles for the different mesh densities are shown in Fig. 6(a). For an element size of $0.05 \mathrm{D}$, the penetration resistance was overestimated significantly. In contrast, load-displacement responses based on element sizes of $0.018 \mathrm{D}$ and $0.025 \mathrm{D}$ converged, suggesting that mesh convergence is achieved with an element size of $0.025 \mathrm{D}$.

The penetration rate specified to result in a quasi-static analysis must be sufficiently slow, however, the computational cost increases with reduced penetration rate (Tho et al. 2012). The penetration resistance profiles for different penetration rates of $0.1,0.2,0.5$ and $1 \mathrm{~m} / \mathrm{s}$ are shown in Fig. 6(b). The profiles corresponding to the penetration rates of 0.1 and $0.2 \mathrm{~m} / \mathrm{s}$ show divergence of less than $2 \%$. When the spudcan diameter is larger than $6 \mathrm{~m}$, the inertial effect will become increasingly negligible.

Based on these sensitivity analyses, an element size close to the spudcan of $0.025 \mathrm{D}$ and spudcan penetration rate of $0.2 \mathrm{~m} / \mathrm{s}$ were selected for the remainder of the analyses. These parameters balance computational accuracy and efficiency. 


\subsection{Effects of spudcan roughness and $S_{t}$ on penetration resistances}

The effect of spudcan roughness on penetration resistance depends on the soil type. For a rough spudcan in a single clay layer, the penetration resistance is only $\sim 5 \%$ higher than that of a smooth spudcan. In contrast, the roughness of a spudcan has a distinct influence on the penetration resistance in a single sand layer. Qiu and Henke (2011) conducted CEL simulations of spudcan penetration on a single sand layer and found that the penetration resistance was enhanced significantly when the friction coefficient $\alpha$ was increased from 0 to 0.5 but only increased by up to a further $\sim 5 \%$ at deep penetrations for $\alpha>0.5$.

The numerical penetration resistance profiles for sand overlying clay with $\alpha$ of $0,0.5$ and 1 are shown in Fig. 7. Overall, the resistance profile with $\alpha$ of 0.5 is close to that with $\alpha$ of 1 . The penetration resistance in the clay layer with $\alpha=0$ is significantly lower than those with $\alpha=0.5$ and 1 , with the divergence becoming increasingly apparent with increasing penetration depth (with a maximum difference of $22 \%$ at $d / D=2.3$ ). The peak penetration resistance, $\mathrm{q}_{\text {peak }}$, which appears in the sand layer, is almost independent of the spudcan roughness. The peak penetration resistance of a smooth spudcan $(\alpha=0)$ appears marginally higher than those of intermediate or fully rough spudcans. The potential cause of this difference is the greater amount of soil flow in the sand layer leading to more strength of mobilization in the layer, while for the rough spudcan such mobilization is not obvious and the failure mechanism concentrates mainly at the layer interface. When the spudcan is penetrated into the clay layer, stronger sand is trapped beneath the advancing spudcan, and the shape and volume of the sand plug depends on the roughness of the spudcan. Compared with the smooth spudcan, more sand is trapped beneath the frictional spudcan, and the sand plug transfers the loading to deeper soil with higher local undrained strength. A roughness of $\alpha=0.5$ was used in the following analyses to capture this effect.

Another potential concern in these simulations is that the shaft is treated as frictional like the spudcan to faithfully simulate the experiments of $\mathrm{Hu}$ et al. (2014), where the vertical load was measured at the top of the shaft. The impact of this detail was considered by performing an additional analysis for the smallest (6 m diameter) spudcan (for which the impact of friction on the shaft is largest given the same shaft was used for all spudcan sizes). In this analysis, the spudcan was assumed frictional with $\alpha=0.5$, while the shaft was frictionless. At a penetration depth of $\mathrm{H}_{\mathrm{s}}+$ $\mathrm{D}$ (a depth relevant to the interpretation of bearing capacity factors in the underlying clay layer presented later), the penetration resistance was reduced by no more than $7 \%$ for the frictionless shaft analyses compared to the frictional shaft counterpart. This result indicates that the impact of friction on the shaft was minimal. 
For most offshore soft to medium soft clays, the typical range of soil sensitivity is $S_{t}$ of 2 - 5 (Kvalstad et al. 2001; Andersen and Jostad, 2004). The sensitivity of kaolin clay in centrifuge tests was measured by Hu et al. (2014) as $S_{t}$ of 3, which is close to $S_{t}$ of 2.5 by Zhang et al. (2011) and $S_{t}$ of 2 - 2.5 by Gan et al. (2012) for the same soil. The penetration resistance profiles for $S_{t}$ of 1,3 and 5 are shown in Fig. 8. The profiles with $S_{t}$ of 3 and 5 are nearly identical, while the penetration resistance is increased by $9 \%$ when the sensitivity is reduced from 3 to 1 . A sensitivity of 3 is adopted in the following analyses for consistency with the experimentally measured sensitivity.

\subsection{Full penetration resistance profiles}

All 15 centrifuge tests reported by Hu et al. (2014) were grouped with three sand layer thicknesses: $\mathrm{H}_{\mathrm{s}}$ of 3.2, 5 and $6 \mathrm{~m}$. Two typical experimental penetration resistances for each sand layer height and corresponding numerical simulations are plotted in Fig. 9. Reasonable agreement is broadly evident between the CEL results and experiments. From touchdown of the tip of the spudcan to full embedment into the sand surface, the penetration resistance increases insignificantly, and soil flow is constrained within the sand layer. After the LRP touches the sand, the penetration resistance begins to be rapidly mobilized up to the peak resistance, $\mathrm{q}_{\text {peak }}$, at a penetration depth of $0-2 \mathrm{~m}$ in the sand layer. The magnitude of $\mathrm{q}_{\text {peak }}$ depends on both the sand and clay strengths because, at this point, the sand frustum beneath the spudcan is being pushed into the underlying clay layer. The penetration resistance remains approximately constant or reduces slightly until the LRP of the spudcan penetrates into the underlying clay layer. The punch-through mechanisms observed in the centrifuge tests are generally captured by the simulations, despite the resistances in clay layer being overestimated for some cases. Following penetration of the spudcan and sand plug into the clay layer, the penetration resistance tends to increase proportionally with depth, which is mainly attributed to the linear increase in clay strength with depth. This result suggests that the shape of the composite spudcan and sand plug foundation is essentially stable; thus, the bearing capacity factor may remain constant with depth.

\subsection{Peak resistance and sand plug height}

The peak resistance and corresponding penetration depth must be quantified in routine designs. The peak resistances measured in the centrifuge tests and predicted by the CEL approach and a modified failure stress-dependent model ( $\mathrm{Hu}$ et al. 2014, and summarized in Section 6 of this paper) are compared in Fig. 10. The predictions from the numerical analyses and analytical model are in reasonable agreement within bounds of $\pm 15 \%$. The CEL analyses generally slightly under-predict the experimental peak resistance due to the assumption in the CEL analyses that the friction angle of sand is equal to the critical value. The analytical model calculations for the same experiments indicate transient operative friction angles slightly higher, $33^{\circ}-34^{\circ}$ at peak resistance. The critical 
friction angle was used here to appropriately model the shape and volume of the trapped sand plug where the sand at the periphery would be at the critical state (Li et al. 2013).

During penetration in the clay layer, the height of the sand plug, $\mathrm{H}_{\text {plug }}$, is important, as it influences the bearing capacity factor and the buoyancy term of Eq. $1 . \mathrm{H}_{\text {plug }}$ is a function of soil properties, spudcan diameter and test geometry. For the centrifuge experiments described by $\mathrm{Hu}$ et al. (2014), all test locations were dissected to examine the deposited height of the trapped sand plug left in the clay after spudcan extraction. Typical sand plug geometries from tests L1SP1 and L1SP4 and the corresponding CEL simulations are presented in Fig. 11. All the sand plug heights $\mathrm{H}_{\text {plug }}$ inferred from the numerical simulations are close to those determined in the post-test measurements illustrated in Fig. 12(a), while Fig. 12(b) shows that both the experimental and CEL analyses resulted, on average, in trapped sand plug heights that were $90 \%$ of the sand layer thickness. This result is close to the value of $\sim 1 \mathrm{H}_{\mathrm{s}}$ observed by Teh et al. (2008) and agrees with the upper bound estimated by Lee (2009). The bearing capacity in the clay layer, accounting for buoyancy, can thus be expressed as

$$
\mathrm{q}_{\text {clay }}=\mathrm{N}_{\mathrm{c}} \mathrm{s}_{\mathrm{u} 0}+\mathrm{H}_{\text {plug }} \gamma_{\mathrm{c}}^{\prime}=\mathrm{N}_{\mathrm{c}} \mathrm{s}_{\mathrm{u} 0}+0.9 \mathrm{H}_{\mathrm{s}} \gamma_{\mathrm{c}}^{\prime} \quad\left(0.16 \leq \frac{\mathrm{H}_{\mathrm{s}}}{\mathrm{D}} \leq 1\right)
$$

\section{Parametric studies}

\subsection{Influences of sand thickness and undrained strength of clay}

Before predicting the full penetration resistance profile, the influences of several critical factors $\left(\mathrm{H}_{\mathrm{s}} / \mathrm{D}, \mathrm{s}_{\mathrm{um}}\right.$ and $\left.\mathrm{k}\right)$ were quantified within realistic bounds relative to offshore practices. A complementary set of parametric analyses were thus performed in addition to the experimental simulations, geometric and soil property details of which are listed in Table 2 . The sand thickness ratio $\mathrm{H}_{\mathrm{s}} / \mathrm{D}$ was varied from 0.3 to 0.9 ; clay strength at the sand-clay interface $\mathrm{s}_{\mathrm{um}}$ from 10 to $40 \mathrm{kPa}$; clay shear strength gradient $\mathrm{k}$ from 1 to $2 \mathrm{kPa} / \mathrm{m}$; and operative friction angle $\phi^{\prime}$ from $30^{\circ}$ to $33^{\circ}$ (representative of typical critical friction angles for siliceous sands). The spudcan geometry (Fig. 4) was identical to that used in the experiments reported by Hu et al. (2014).

The normalized sand thickness, $\mathrm{H}_{\mathrm{s}} / \mathrm{D}$, has an obvious influence on the penetration resistance, as shown in Fig. 13(a). A punch-through potential is observed at $\mathrm{H}_{\mathrm{s}} / \mathrm{D}=0.7$, with a reduction in penetration resistance predicted during the vertical penetration. An approximately constant peak penetration resistance over the penetration depth is observed in the case of $\mathrm{H}_{\mathrm{S}} / \mathrm{D}=0.6$. In the jackup industry this is often referred to as a rapid-leg-run event. For smaller sand thicknesses, such as $\mathrm{H}_{\mathrm{s}} / \mathrm{D}=0.3$, safe installation is possible. This trend is due to the magnitudes of the sources of resistance that comprise $\mathrm{q}_{\text {peak }}$. For larger $\mathrm{H}_{\mathrm{s}} / \mathrm{D}$, shearing in the sand layer provides a far larger 
proportion of $\mathrm{q}_{\text {peak }}$ than the bearing capacity of the underlying clay layer. In contrast, for small $\mathrm{H}_{\mathrm{s}} / \mathrm{D}$, the clay bearing capacity is dominant and provides the majority of $\mathrm{q}_{\text {peak. }}$. The clay bearing capacity is mainly dependent upon $s_{u m}$ and $\mathrm{k}$, which do not change between these analyses; thus, catastrophic punch-through failure is more likely to occur with a higher $H_{s} / D$, as the difference between peak and post-peak resistance is greatest. Figure 13(a) also shows that, for different sand thickness ratios, the penetration resistances in the clay layer do not converge due to the differing volume and geometry of the trapped sand plugs beneath the spudcan.

The effects of clay shear strength at the sand-clay interface, $s_{u m}$, and strength gradient $\mathrm{k}$ on the penetration resistance are demonstrated in Fig. 13(b), with $\mathrm{H}_{\mathrm{s}} / \mathrm{D}=0.6$. Rapid-leg-run potential is observed in all cases, and the depths of peak penetration resistance are nearly independent of the undrained strength of clay; however, the deep penetration resistance in the clay layer increases significantly with increasing $\mathrm{s}_{\mathrm{um}}$ or $\mathrm{k}$. For $\mathrm{k}=2 \mathrm{kPa} / \mathrm{m}, \mathrm{H}_{\mathrm{s}} / \mathrm{D}=0.6$ and $\phi^{\prime}=32^{\circ}$, the peak resistance for $\mathrm{s}_{\mathrm{um}}$ of $20 \mathrm{kPa}$ is a factor of $\sim 1.3$ times that for $\mathrm{s}_{\mathrm{um}}$ of $10 \mathrm{kPa}$. After the LRP reaches the original sand-clay interface, the gradient of the penetration resistance profiles is nearly independent of $s_{u m}$, while the increasing rate of penetration resistance is larger for higher $\mathrm{k}$ after the spudcan is fully embedded in the clay layer. These trends are further indication that, for a constant geometric ratio $\mathrm{H}_{\mathrm{s}} / \mathrm{D}$, a constant $\mathrm{N}_{\mathrm{c}}$ should be used.

\subsection{Equation for bearing capacity factor}

When the spudcan and the sand plug penetrate into clay together, the sand plug mobilizes soil with higher soil strength than that at the LRP due to the shear strength of the soil increasing with depth. Thus, the bearing capacity factors for spudcan penetration into a single clay layer are inappropriate for the sand overlying clay scenario investigated here.

Bearing capacity factor $\mathrm{N}_{\mathrm{c}}$ was derived by dividing the bearing pressure by the intact undrained shear strength adopted in both the simulations of the centrifuge tests and the complementary parametric analyses. Both $s_{u 0}$ and $\mathrm{N}_{\mathrm{c}}$ refers to the values at LRP in Fig. 4. When the LRP was penetrated to a depth deeper than $1 \mathrm{D}$ below the sand-clay interface, i.e. $\left(\mathrm{d}-\mathrm{H}_{\mathrm{s}}\right) / \mathrm{D} \geq 1$, it is observed that the spudcan with the sand plug underneath has reached a deep 'steady-state' according to the CEL simulations of all centrifuge tests and complementary parametric studies. The capacity factor at $1 \mathrm{D}$ below sand-clay interface can be fitted linearly against the sand thickness

$$
\mathrm{N}_{\mathrm{c}, \text { deep }}=15 \frac{\mathrm{H}_{\mathrm{s}}}{\mathrm{D}}+9 \quad\left(0.16 \leq \frac{\mathrm{H}_{\mathrm{s}}}{\mathrm{D}} \leq 1\right)
$$

with a coefficient of determination of $\mathrm{R}^{2}=0.93$. This deep factor remains constant with further penetration in clay. 
If the capacity factor at depth of $\left(\mathrm{d}-\mathrm{H}_{\mathrm{s}}\right) / \mathrm{D}<1$ is approximated with Eq. 8 (i.e. $\mathrm{N}_{\mathrm{c}}=\mathrm{N}_{\mathrm{c} \text {,deep }}$ from the depth of sand-clay interface), the capacity factor is very close to the relationship given in Eq. 2 that was fitted against the centrifuge tests for dense sand overlying clay (Lee et al. 2013a). Figure 14 demonstrates the normalized $\mathrm{N}_{\mathrm{c}}$ profiles from the sand-clay interface to a depth of $2 \mathrm{D}$ below the sand-clay interface. In this figure, the capacity factor near the sand-clay interface $\left(\mathrm{d}=\mathrm{H}_{\mathrm{s}}\right)$ tends to be higher than $\mathrm{N}_{\mathrm{c}, \text { deep. }}$. This is due to the trapped sand plug not being fully formed, causing some extra sand to shear close to the sand-clay layer interface. However, the typical depth at the end of punch-through events, as demonstrated below, is deeper than the depths affected by the incomplete formation of the sand plug. Hence, for simplicity, $\mathrm{N}_{\mathrm{c}}$ might be set equal to that estimated using Eq. 8. For the majority of the analyses, the simple linear expression describes the bearing capacity factor with depth to within $\pm 10 \%$ of the back-calculated values.

It should be noted that Eq. 8 was summarized for $\mathrm{H}_{\mathrm{s}} / \mathrm{D}$ of 0.16 to $1, \phi^{\prime}$ of 30 to $33^{\circ}$, $\mathrm{s}_{\mathrm{um}}$ of 10 to 40 $\mathrm{kPa}, \mathrm{k}$ of 1 to $2 \mathrm{kPa} / \mathrm{m}$ and sensitivity $\mathrm{S}_{\mathrm{t}}$ in the range of 3 to 5 , all of which represent practical ranges of soil properties for offshore locations, where punch-through failure are potential risks. This equation may not be valid outside of these bounds or for soils with significantly differing behaviors (such as carbonate silts or highly sensitive clays).

\section{Simplified method for prediction of full penetration resistance profile}

\subsection{A simplified full profile prediction method}

A simplified method for prediction of a penetration resistance profile for spudcan foundations on sand overlying clay is useful in the evaluation of the potential severity of a punch-through failure. The construction of a simplified resistance profile requires preliminary knowledge of three critical stages in $q \sim d$ space: i) the penetration resistance from the tip of the spudcan touching the soil until the spudcan spigot (if present) is fully embedded, (ii) the peak resistance in the sand layer, qpeak, and (iii) the penetration resistance when the LRP is at the depth of the original sand-clay interface $(d=$ $\mathrm{H}_{\mathrm{s}}$ ) and beyond. At stage (i), the resistance can be assumed to be zero for simplicity because the contribution of a small spigot to the overall capacity is negligible, and the corresponding penetration depth is the height of the spigot. At stage (ii), the modified failure stress-dependent model of Hu et al. (2014) can be utilized

$$
\begin{aligned}
& \mathrm{q}_{\mathrm{peak}}=\left(\mathrm{N}_{\mathrm{c} 0} \mathrm{~s}_{\mathrm{um}}+\mathrm{q}_{0}+0.12 \gamma_{\mathrm{s}}^{\prime} \mathrm{H}_{\mathrm{s}}\right)\left(1+\frac{1.76 \mathrm{H}_{\mathrm{s}}}{\mathrm{D}} \tan \psi\right)^{\mathrm{E}^{*}} \\
& +\frac{\gamma_{s}^{\prime} \mathrm{D}}{2 \tan \psi\left(\mathrm{E}^{*}+1\right)}\left[1-\left(1-\frac{1.76 \mathrm{H}_{\mathrm{s}}}{\mathrm{D}} \mathrm{E}^{*} \tan \psi\right)\left(1+\frac{1.76 \mathrm{H}_{\mathrm{s}}}{\mathrm{D}} \tan \psi\right)^{\mathrm{E}^{*}}\right]
\end{aligned}
$$


where $\mathrm{N}_{\mathrm{c} 0}$ is the bearing capacity factor for clay at the base of a circular foundation, which is obtained using the relationship proposed by Houlsby and Martin (2003) for circular foundations with shear strength increasing linearly with depth, and $\mathrm{q}_{0}$ is the effective overburden pressure at the depth of the foundation. $\mathrm{E}^{*}$ is a parameter to simplify the algebra:

$$
\mathrm{E}^{*}=2\left[1+\mathrm{D}_{\mathrm{F}}\left(\frac{\tan \phi^{*}}{\tan \psi}-1\right)\right]
$$

where $D_{F}$ is a distribution factor that relates the local stress along the failure surface to the average vertical stress, or the ratio of the normal effective stress at the slip surface to the mean vertical effective stress, and $\phi^{*}$ is a reduced friction angle caused by non-associated flow that can be expressed as (Drescher and Detournay, 1993):

$$
\tan \phi^{*}=\frac{\sin \phi^{\prime} \cos \psi}{1-\sin \phi^{\prime} \sin \psi}
$$

The depth of the peak penetration resistance, $\mathrm{d}_{\text {peak }}$, is $0.12 \mathrm{H}_{\mathrm{s}}$, as suggested by Teh et al. (2010) and verified through centrifuge tests for dense and medium dense sand overlying clay (Hu et al. 2014). For stage (iii) and beyond, the penetration resistance is calculated by substituting $\mathrm{N}_{c}$, deep in Eq. 8 for Nc in Eq. 7. The depth of the punch-through event is thus the depth at which the capacity by Eq. 7 is equal to $\mathrm{q}_{\text {peak }}$ minus $\mathrm{d}_{\text {peak }}$.

\subsection{Performance of the simplified prediction method}

To explore the performance of the proposed simplified prediction method, both the resistance profile and the depths of punch-through event were compared for 20 centrifuge tests of sand overlying clay in Table 1 (15 for medium dense sand overlying clay from Hu et al. (2014) and 5 for dense sand overlying clay from Lee et al. (2013a)). Figure 15 demonstrates the comparisons for two pairs of typical tests from medium dense sand overlying clay and dense sand overlying clay. In general, the initial sharp increase in the resistance on sand and the resistance in the clay layer are predicted reasonably well for the four cases. This validates the model of $\mathrm{Hu}$ et al. (2014) for $\mathrm{q}_{\text {peak }}$ prediction and the equation proposed here for $\mathrm{q}_{\text {clay }}$ (Eq. 7 and 8). If the depth of the peak resistance is also known, which has been demonstrated to be readily predicted (Hu et al. 2014: Fig. 6 and Eq. 3 ), the potential maximum depth of a punch-through event from onset until equilibrium is reestablished can be estimated. It is acknowledged that for jack-up units that can perform preloading at draft this maximum distance may not be the primary concern, and the shape of the resistance profile after peak may be more critical. Though this is not provided in this simplified approach, the

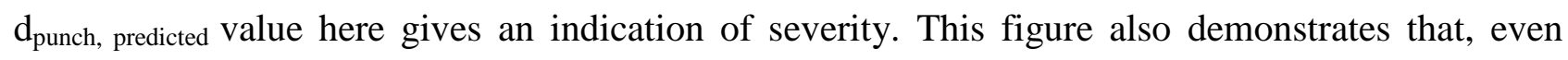
though it was derived from CEL simulations for loose and medium dense sand overlying clay, the 
simple prediction model for bearing capacity in the clay layer still appears valid for dense sand overlying clay scenarios. The soil at the periphery of the sand plug have reached the critical state during penetration in the clay layer - irrespective of the initial relative density of the sand layer due to the cumulative shearing to which it is subjected. Hence, simulations setting the operative friction angle equal to the critical value also appear valid for dense sand overlying clay. It would be beneficial in the future to simulate the dense sand overlying clay centrifuge tests using a constitutive model for the sand that can account for strain hardening and softening.

The predictions of the simplified method for both medium dense and dense sand tests are also presented in terms of $d_{\text {punch, predicted }} / d_{\text {punch, test }}$ in Fig. 16. Though the predictions from the simplified method underestimate the uncontrolled penetration depth, the under-prediction is less than $20 \%$ for the majority of the tests. Even with an under-prediction of $20 \%$, the method clearly allows a relatively fast and accurate prediction of the depth of a punch-through event that can be compared against the operability limits of the jack-up rig. All parameters are routinely derived during site investigation campaigns prior to jack-up rig deployment. It should be noted that the framework presented is verified by centrifuge tests of medium dense and dense sand overlying kaolin clay; more testing and field data with a wider range of material properties would further validate its performance.

\section{Conclusions}

This paper reports the results of CEL simulations of centrifuge tests, investigating the potential for punch-through of spudcan foundations during deep penetration through a sand layer into an underlying clay layer. Generally reasonable agreement was obtained between the results of centrifuge tests and CEL analyses in terms of penetration resistance profiles. A simplified prediction method with straightforward algebraic expressions and clearly defined parameters for producing a complete simplified penetration resistance profile for foundations on sand overlying clay has been presented.

By incorporating strain softening clay constitutive model in the simulation, both punch-through and rapid-leg-run potential in medium dense sand overlying clay centrifuge tests were replicated. The contact property was shown to have only a small effect on $\mathrm{q}_{\text {peak }}$, though more significant differences in $\mathrm{q}_{\text {clay }}$ were found for smooth and frictional cases in which the spudcan was fully embedded into the clay layer. The sensitivity of the clay, $S_{t}$, had a small effect on the penetration resistance when within the range of $3 \leq S_{t} \leq 5$.

Using complementary parametric analyses, the effects of $\mathrm{H}_{\mathrm{s}} / \mathrm{D}, \mathrm{k}$ and $\mathrm{s}_{\mathrm{um}}$ on the penetration resistance profile were investigated. $\mathrm{H}_{\mathrm{s}} / \mathrm{D}$ mainly controls the pattern of failure potential, with 
larger values being more prone to punch-through failure (reduction of vertical load with depth), while rapid-leg-run (approximately constant peak load with depth) is more likely for smaller values of $\mathrm{H}_{\mathrm{s}} / \mathrm{D}$. When $\mathrm{H}_{\mathrm{s}} / \mathrm{D}$ was further decreased, a non-linear increase of the penetration resistance was apparent, indicating no punch-through or rapid-leg-run potential. The deep penetration resistance, $\mathrm{q}_{\text {clay }}$, increased significantly with increasing $\mathrm{s}_{\mathrm{um}}$, while the gradient of $\mathrm{q}_{\text {clay }}$ was largely independent of $s_{u m}$ for clay with the same $k$. A linear expression for the bearing capacity factor for the spudcan and underlying plug is summarized from numerical simulations of centrifuge tests and complementary analyses. The equation is based on the geometric conditions and material properties relevant to spudcan punch-through and should be used with caution for any cases beyond the conditions explored in this manuscript (such as non-siliceous sands or highly sensitive clays).

In the simplified prediction method, for penetration resistance in the upper sand layer, the stress level and dilatant response as well as the embedment depth are taken into account; for penetration in the underlying clay, the proposed design equations incorporate the shear strength increment with depth and the thickness of the trapped sand beneath the foundation. In retrospectively calculating the penetration resistance profiles for all 15 medium dense sand and 5 dense sand centrifuge tests, the predicted full penetration resistance profiles show generally good agreement with the testing profiles. The simplified prediction method under-predicts the rapid penetration depth by less than $20 \%$.

\section{Acknowledgements}

This work forms part of the activities of the Centre for Offshore Foundation Systems (COFS), which is supported by the Lloyd's Register Foundation as a Centre of Excellence and now forms one of the primary nodes of the Australian Research Council (ARC) Centre of Excellence for Geotechnical Science and Engineering. Lloyd's Register Foundation invests in science, engineering and technology for public benefit, worldwide. This project has received additional support from the Australia-China Natural Gas Technological Partnership Fund and the ARC Discovery program. The authors are grateful for this support.

\section{References}

Anderson, K.H. and Jostad, H.P. (2004). "Shear strength along inside of suction anchor skirt wall in clay." Proceedings of the Offshore Technology Conference, Houston, OTC 16844.

Bolton, M.D. (1986). “The strength and dilatancy of sands.” Géotechnique, 36(1), 65-78.

Cassidy, M.J. (2012). "Experimental observations of the penetration of spudcan footings in silt.” Géotechnique, Vol. 62, No. 8, pp. 727-732.

Cassidy, M.J. and Houlsby G.T. (2002). "Vertical bearing capacity factors for conical footings on sand." Géotechnique, 52(9), 687-692.

Dassault Systèmes (2011). “ABAQUS analysis user’s manual.” Simulia Corp., Providence, RI. 
Drescher, A. and Detournay, E. (1993). "Limit load in translational failure mechanics for associative and nonassociative materials." Géotechnique, 43(3), 443-456.

Einav, I. and Randolph, M.F. (2005). "Combining upper bound and strain path methods for evaluating penetration resistance.” Int. J. Numer. Methods Eng, 63(14), 1991-2016.

Finnie, I.M.S. and Randolph, M.F. (1994). "Punch-through and liquefaction induced failure of shallow foundations on calcareous sediments.” Proc., Int. Conf. on Behaviour of Offshore Structures, Boston, 217-230.

Gan, C.T., Leung, C.F., Cassidy, M.J., Gaudin, C. and Chow, Y.K. (2012). "Effect of time on spudcan-footprint interaction in clay." Géotechnique, 62(5), 401-413.

Hossain, M.S. and Randolph, M.F. (2009). "Effect of strain rate and strain softening on the penetration resistance of spudcan foundations on clay." Int. J. Geomech., 9(3), 122-32.

Houlsby, G.T, and Martin, C.M. (2003). "Undrained bearing capacity factors for conical footings on clay." Géotechnique, 53(5), 513-520.

Hu, P., Stanier, S.A., Cassidy, M.J. and Wang, D. (2014). "Predicting the peak resistance of a spudcan penetrating sand overlying clay.” J. Geotech. Geoenviron. Eng, 140(2), 04013009.

ISO. (2012). "Petroleum and natural gas industries - site-specific assessment of mobile offshore units - part 1: jack-ups." International Organization for Standardization, ISO 19905-1.

Kvalstad, T.J., Nadim, F. and Harbitz, C.B. (2001). "Deepwater geohazards: geotechnical concerns and solutions." Proceedings of the Offshore Technology Conference, Houston, OTC 16844.

Lee, K.K. (2009). "Investigation of potential spudcan punch-through failure on sand overlying clay soils." Ph.D. thesis. Univ of Western Australia, Perth, Australia.

Lee, K.K., Cassidy, M.J. and Randolph, M.F. (2013a). "Bearing capacity on sand overlying clay soils: Experimental and finite element investigation of potential punch-through failure." Géotechnique, 63(15), 1271-1284.

Lee, K.K., Randolph, M.F. and Cassidy, M.J. (2013b). "Bearing capacity on sand overlying clay soils: A simplified conceptual model." Géotechnique, 63(15), 1285-1297.

Li, X., Hu, Y. and White, D.J. (2013). "Extension of Mohr-Coulomb model into state dependent softening of sand and its application in large deformation finite element analysis." Proceedings of the 2nd International Symposium on Constitutive Modelling of Geomaterials: Advances and Applications, Beijing, Vol. 1, pp. 583-591.

Low, H.E., Randolph, M.F., DeJong, J.T., and Yafrate, N.J. (2008). "Variable rate full-flow penetration tests in intact and remolded soil." Proceedings of the 3rd International Conference on Geotechnical and Geophysical Site Characterization, Taylor and Francis, London, pp. 1087-1092.

Mehryar, Z. and Hu, Y. (2002). "Penetration analysis of spudcan foundation in NC clay." Proceedings of the 12th International Offshore and Polar Engineering Conference, Kitakyushu, Japan.

Osborne, J., Pelley, D., Nelson, C. and Hunt, R. (2006). “Unpredicted jack-up foundation performance.” Proceedings of the 1st Jack-up Asia Conference. Singapore.

Qiu, G. and Grable, J. (2012). "Numerical investigation of bearing capacity due to spudcan penetration in sand overlying clay." Canadian Geotechnical Journal, 49(12): 1393-1407.

Qiu, G. and Henke, S. (2011). "Controlled installation of spudcan foundations on loose sand overlying weak clay." Marine Structures, 24(4), 528-550.

Teh, K.L., Cassidy, M.J., Leung, C.F., Chow, Y.K., Randolph, M.F. and Quah, C.K. (2008). "Revealing the bearing failure mechanisms of a penetrating spudcan through sand overlaying clay." Géotechnique. Vol. 58, No. 10, pp. 793804.

Teh, K.L., Leung, C.F., Chow, Y.K. and Cassidy, M.J. (2010). "Centrifuge model study of spudcan penetration in sand overlying clay." Géotechnique, 60(11), 825-842.

Tho, K.K., Leung, C.F., Chow, Y.K. and Swaddiwudhipong, S. (2009). "Application of Eulerian finite element technique for analysis of spudcan and pipeline penetration into the seabed." Proceedings of the 12th International Jackup Conference, London, 2009.

Tho, K.K., Leung, C.F., Chow, Y.K. and Swaddiwudhipong, S. (2012). "Eulerian finite element technique for analysis of jack-up spudcan penetration." Int. J. Geomech., 12(1), 64-73.

White, D.J., Teh, K.L., Leung, C.F. and Chow, Y.K. (2008). “A comparison of the bearing capacity of flat and conical circular foundations on sand." Géotechnique, 58(10), 781-792. 
Yu, L., Hu, Y., Liu, J., Randolph, M.F. and Kong, X. (2012) "Numerical study of spudcan penetration in loose sand overlying clay." Computers and Geotechnics, 46, 1-12.

Zhang, C.R., White, D.J. and Randolph, M.F. (2011). "Centrifuge modeling of the cyclic lateral response of a rigid pile in soft clay." J. Geotech. Geoenviron. Eng., 137(7), 717-729. 


\section{LIST OF FIGURES}

Fig. 1. (a) Numerical and analytical analyses for spudcan penetration into NC clay; (b) deformed clay strength profile at penetration depth of 3D

Fig. 2. Comparison of CEL with a centrifuge test for spudcan penetration into medium dense sand

Fig. 3. Nomenclature for spudcan foundation penetration in sand overlying clay

Fig. 4. Prototype dimensions of spudcan model (note: the dimensions are absolute values, and the spigot tip to shoulder heights vary with D)

Fig. 5. Typical finite element mesh used in CEL analysis

Fig. 6. (a) Effects of mesh density (b) Effect of penetration rate

Fig. 7. Penetration resistance profiles for different contact properties

Fig. 8. Effect of soil sensitivity on penetration resistance profiles

Fig. 9. Penetration resistance profiles from centrifuge tests and CEL analyses

Fig. 10. Peak penetration resistances from centrifuge tests, CEL analyses and predicted formulations

Fig. 11. Typical deformed sand and clay layers and sand plug heights

Fig. 12. (a) Comparison of calculated and experimental $H_{\text {plug }}$ and (b) relationship between $\mathrm{H}_{\text {plug }}$ and $\mathrm{H}_{\mathrm{s}}$

Fig. 13. Effects of $H_{s} / D, k$ and $s_{u m}$ on penetration resistance profiles

Fig. 14. Bearing capacity factors from CEL simulations of centrifuge tests and parametric studies

Fig. 15. Nomenclature of $d_{\text {punch, test }}$ and $d_{\text {punch, predicted }}$ for (a) medium dense and (b) dense sand tests

Fig. 16. Performance of the simplified prediction method by comparison of rapid penetration depth with that obtained from centrifuge tests 


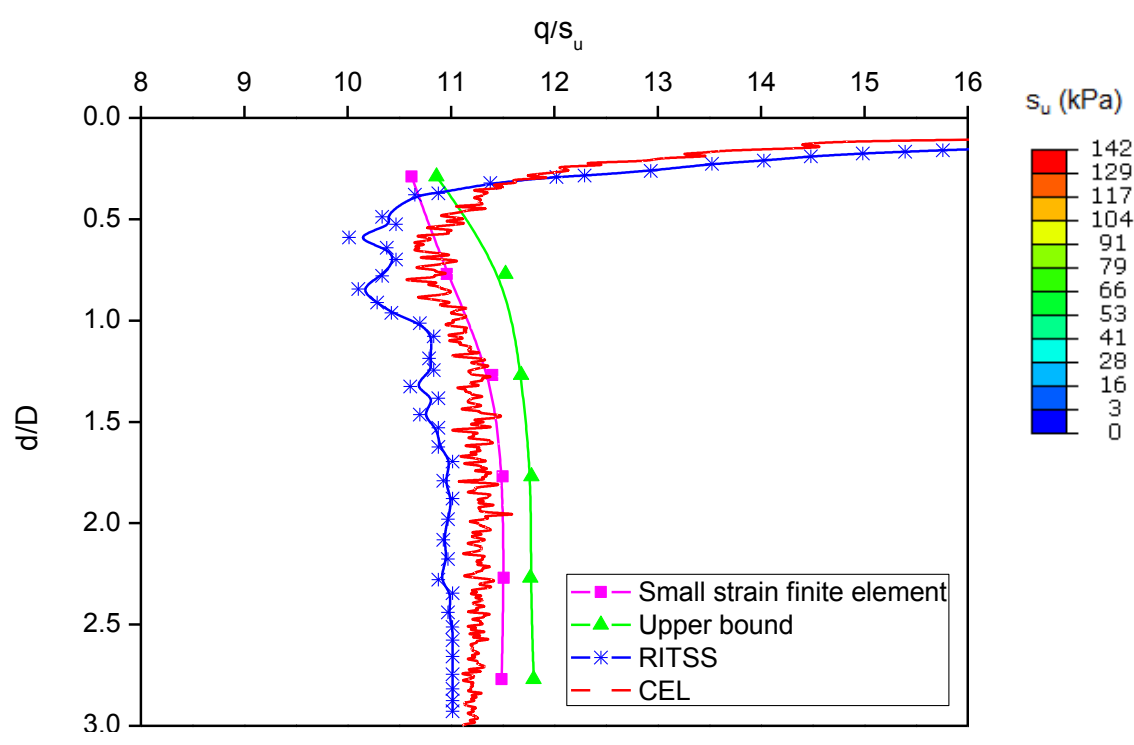

(a)

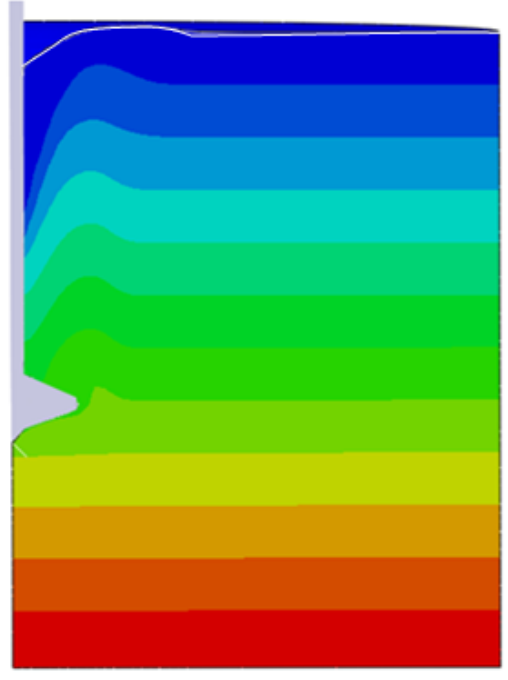

(b)

Fig. 1. (a) Numerical and analytical analyses for spudcan penetration into NC clay; (b) deformed clay strength profile at penetration depth of 3D 


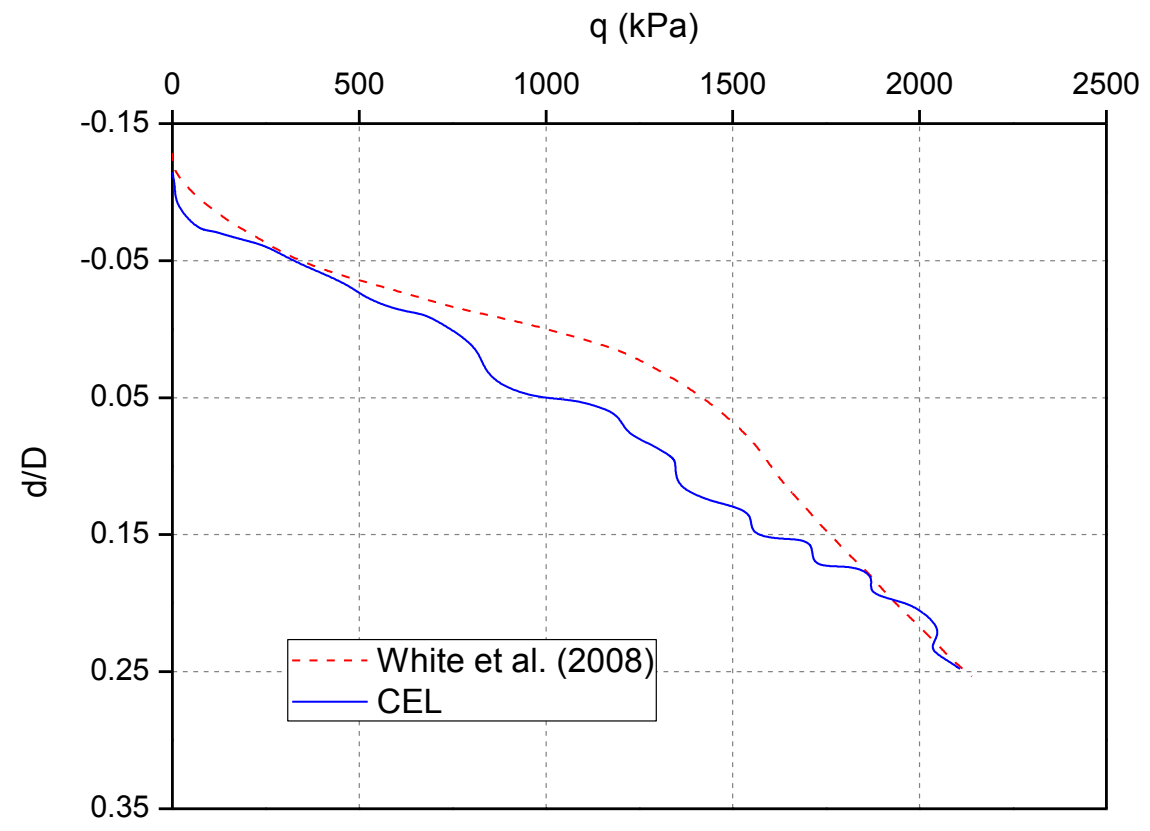

Fig. 2. Comparison of CEL with a centrifuge test for spudcan penetration into medium dense sand 


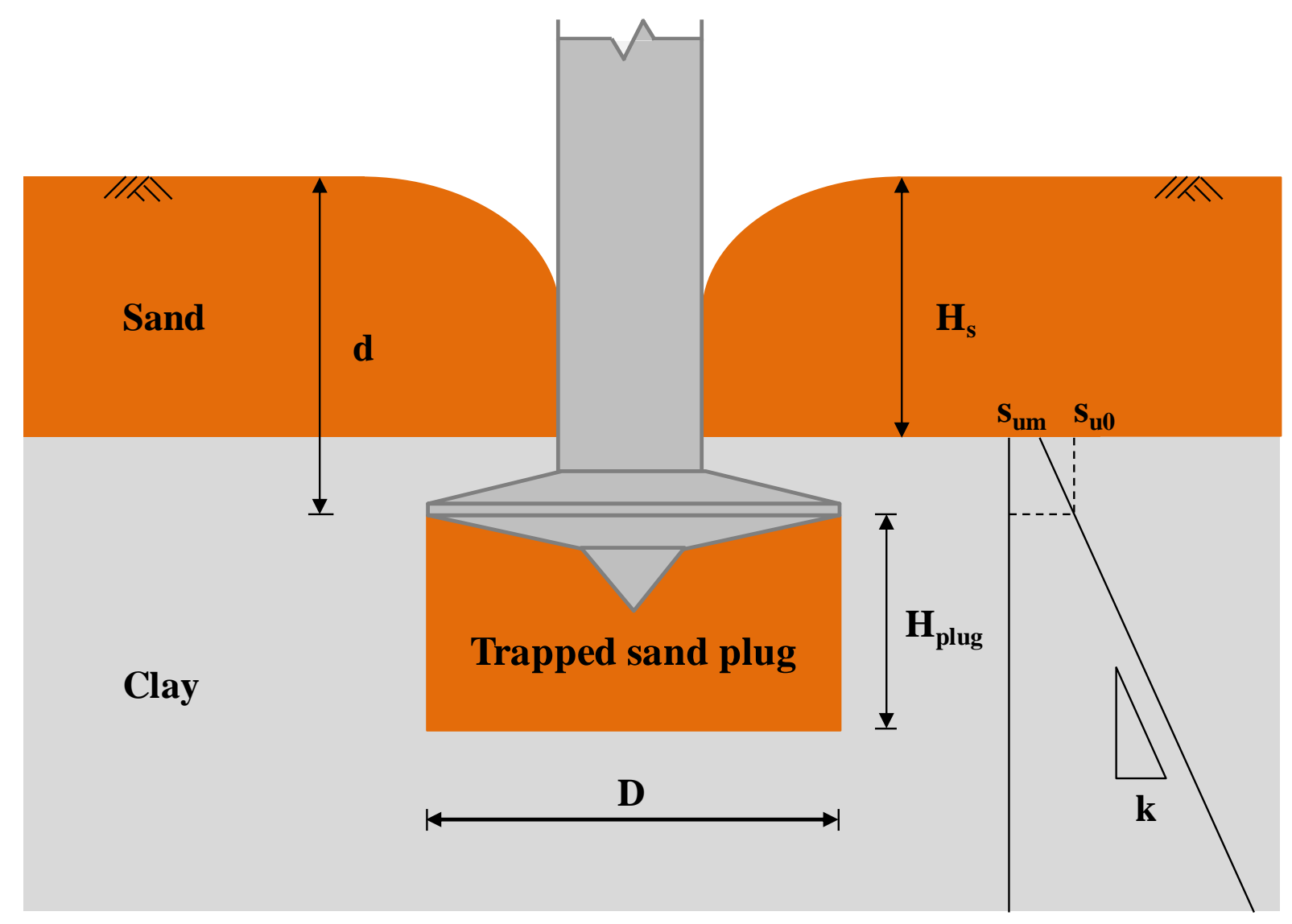

Fig. 3. Nomenclature for spudcan foundation penetration in sand overlying clay 


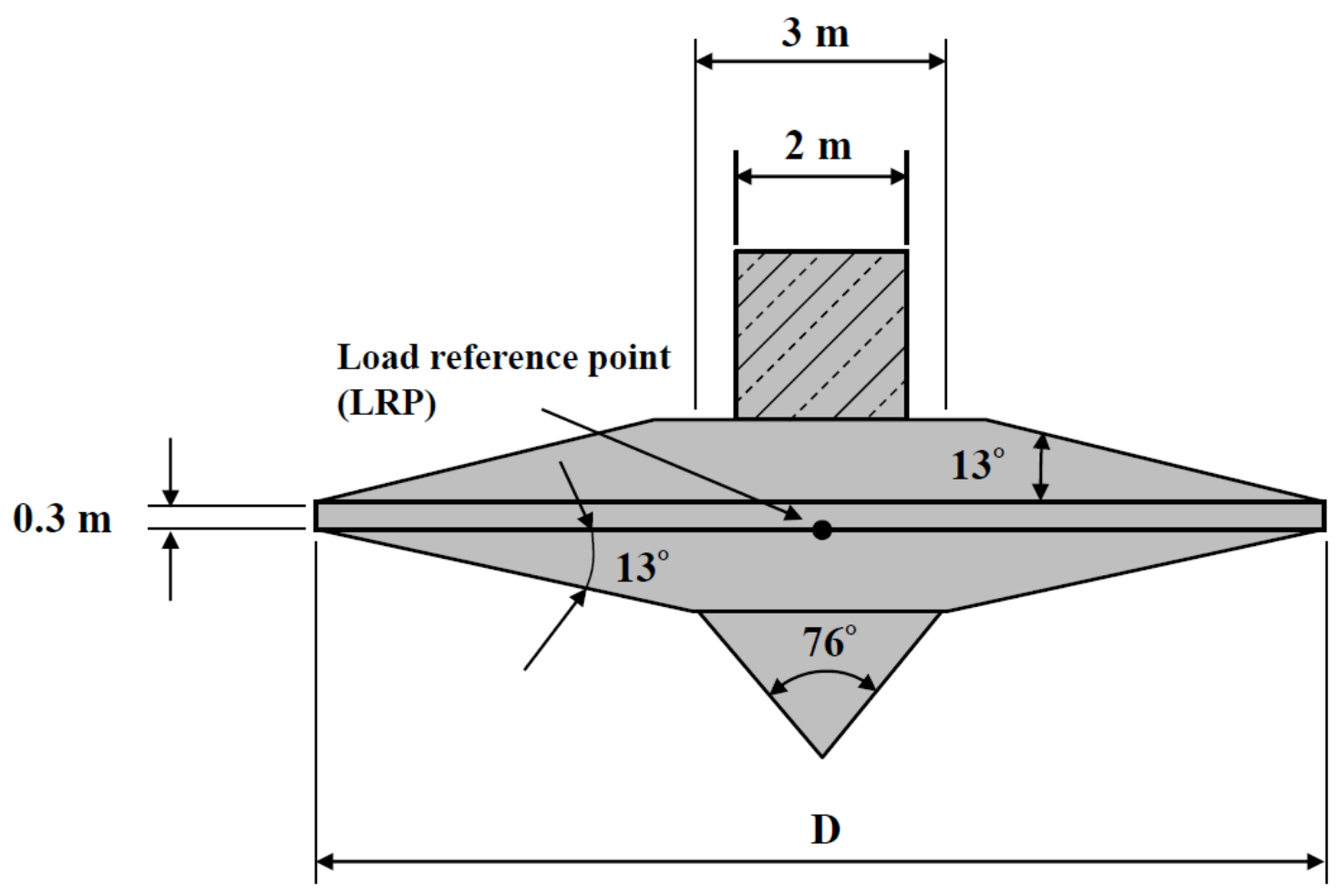

Fig. 4. Prototype dimensions of spudcan model (note: the dimensions are absolute values, and the spigot tip-to-shoulder heights vary with D) 


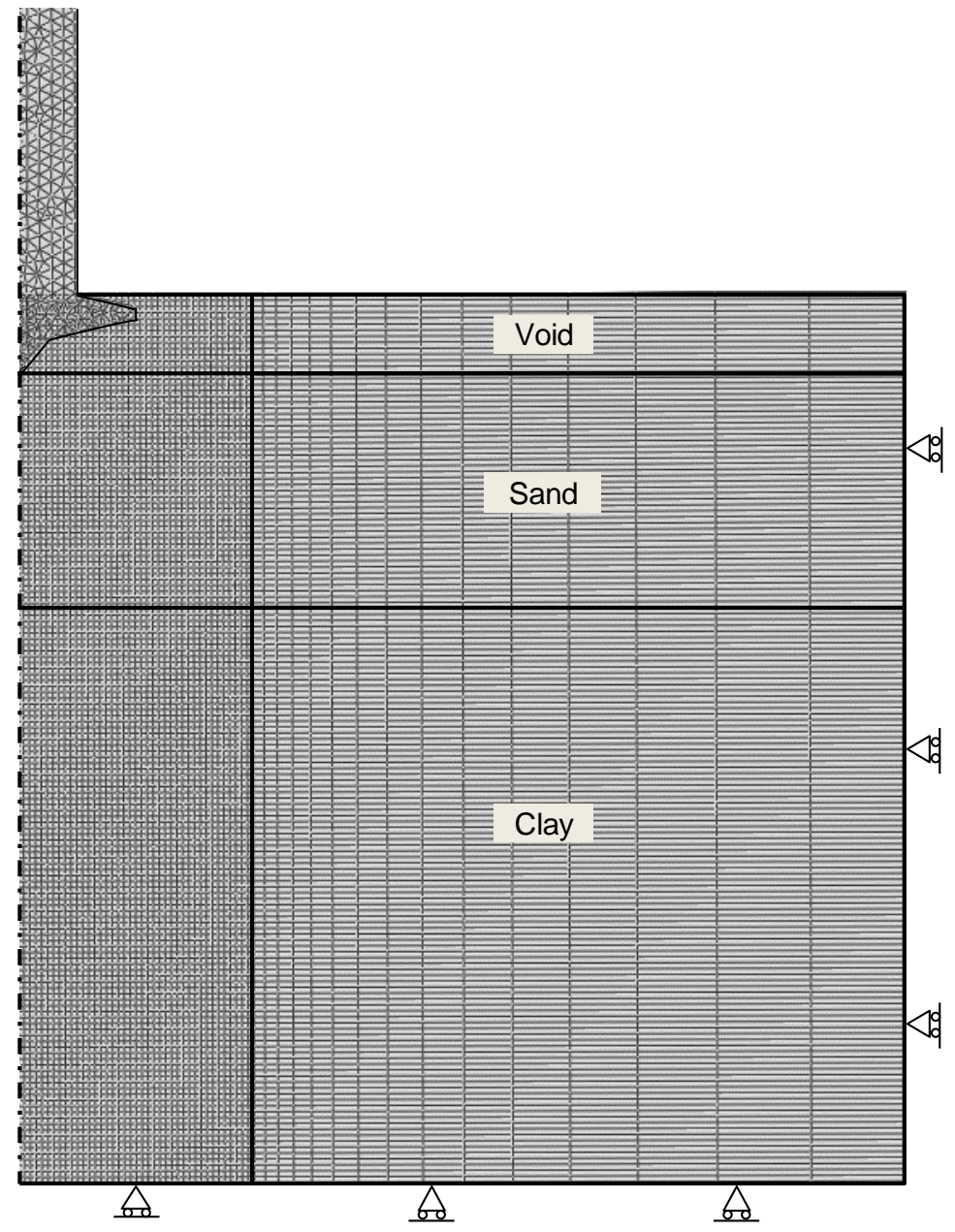

Fig. 5. Typical finite element mesh used in CEL analysis 


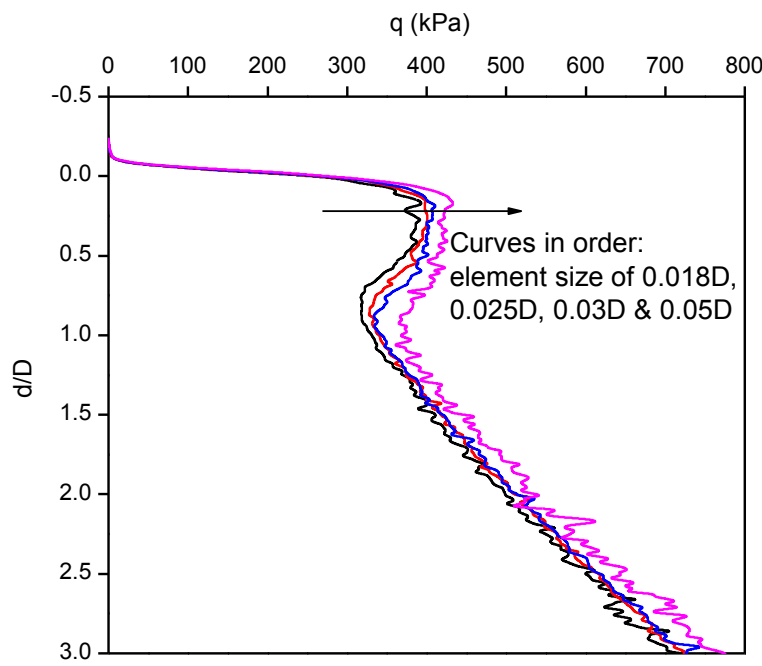

(a)

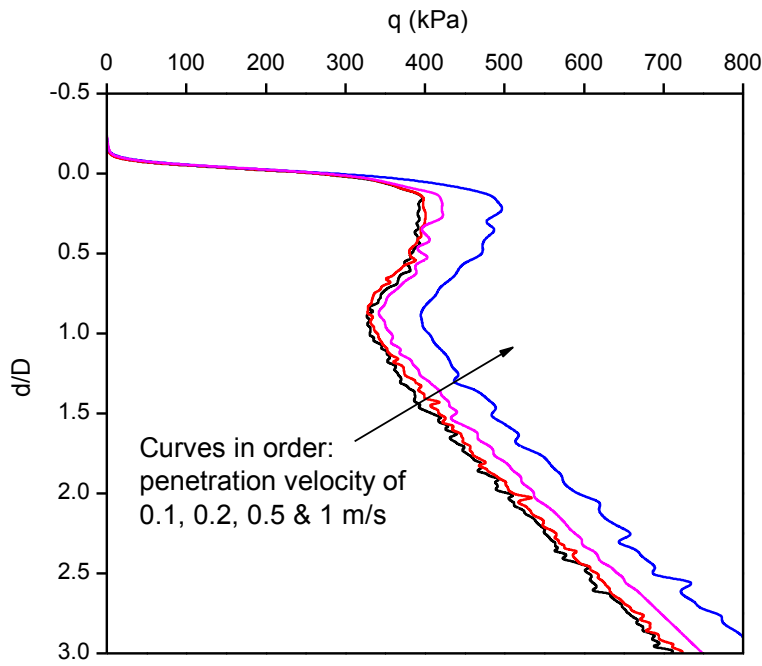

(b)

Fig. 6. (a) Effect of mesh density (b) Effect of penetration rate 


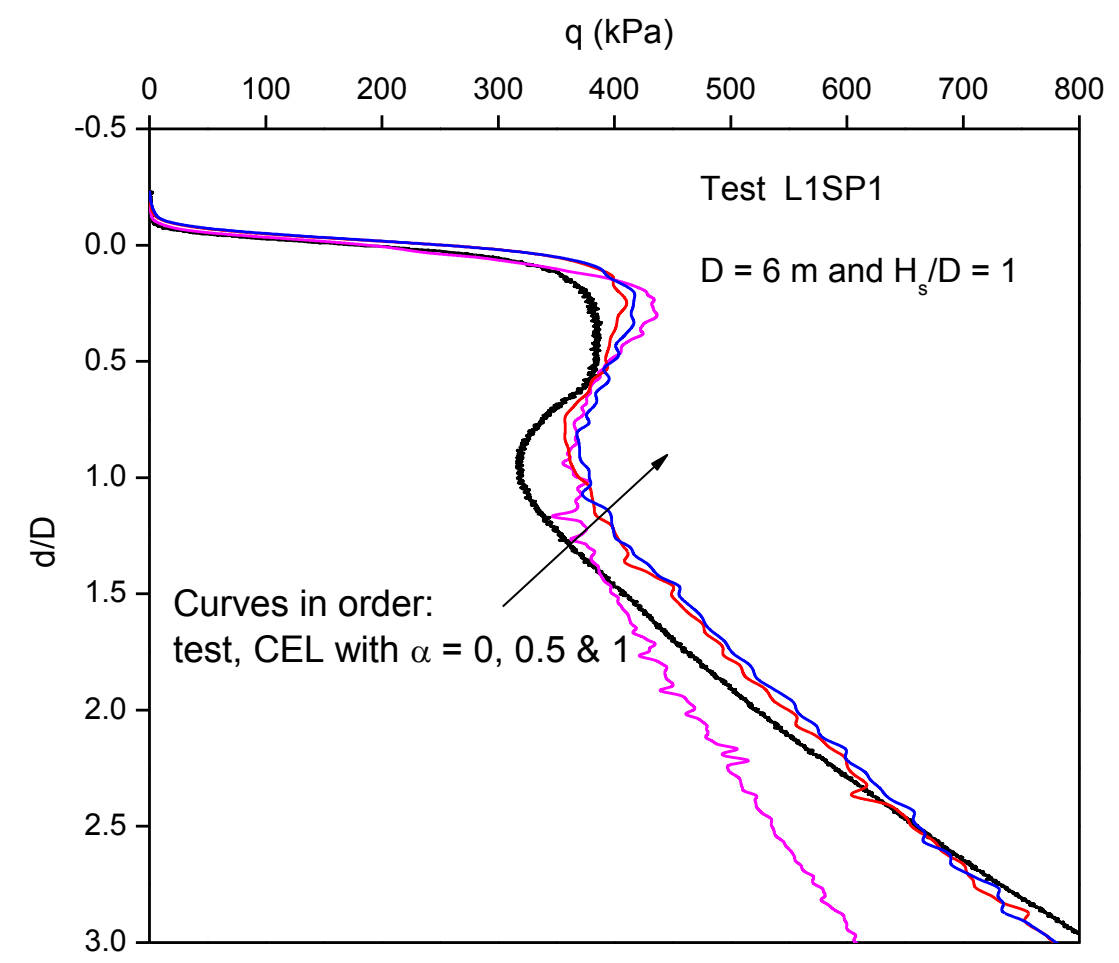

Fig. 7. Penetration resistance profiles for different contact properties 


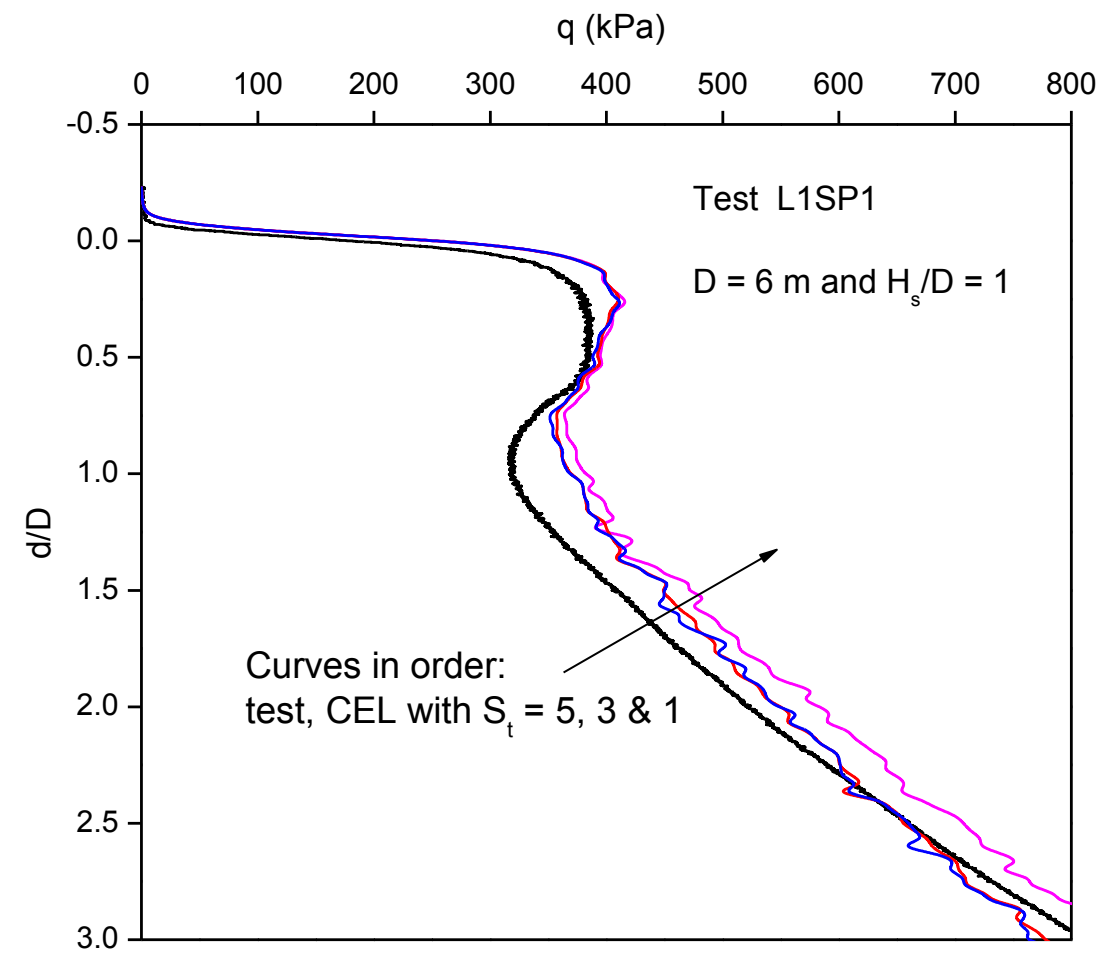

Fig. 8. Effect of soil sensitivity on penetration resistance profiles 


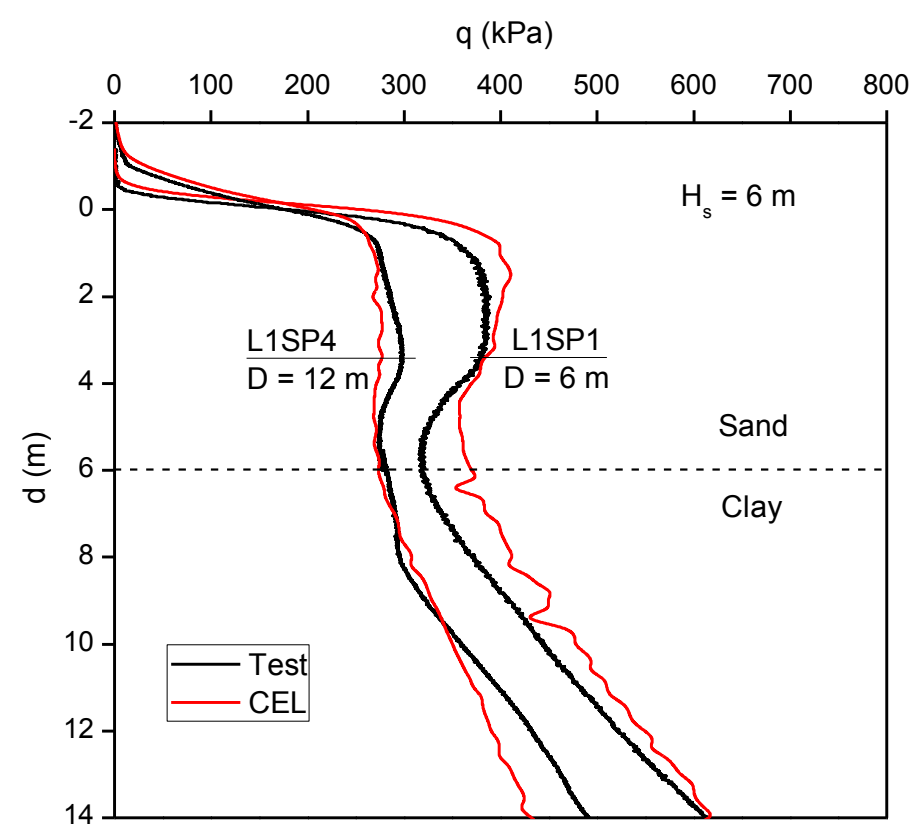

(a)

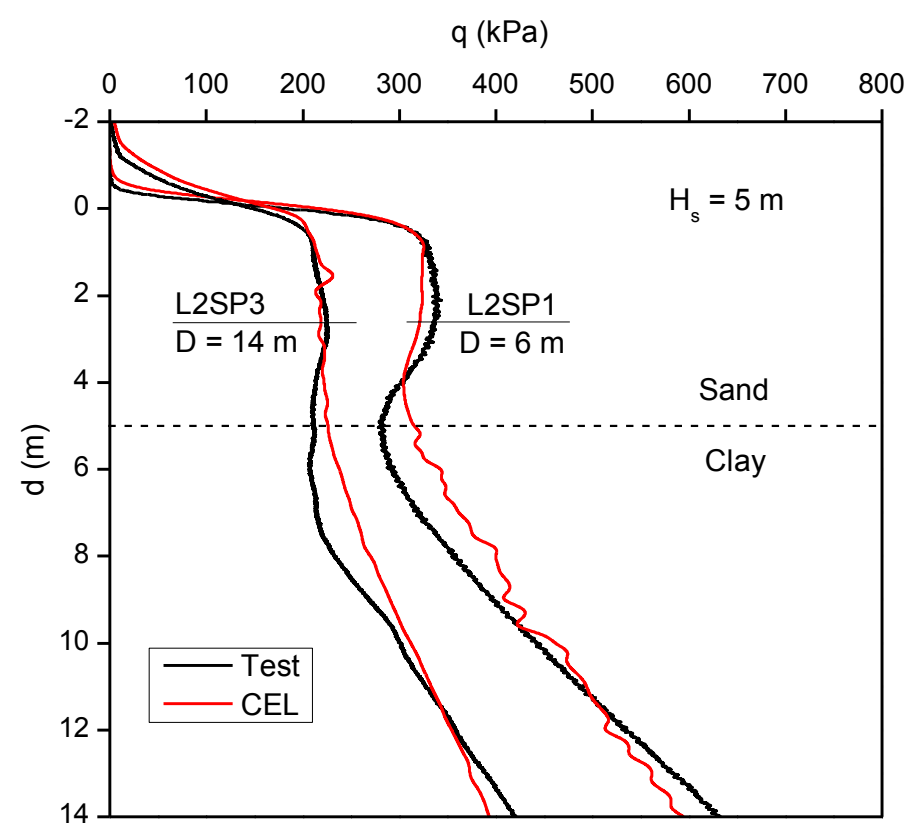

(b)

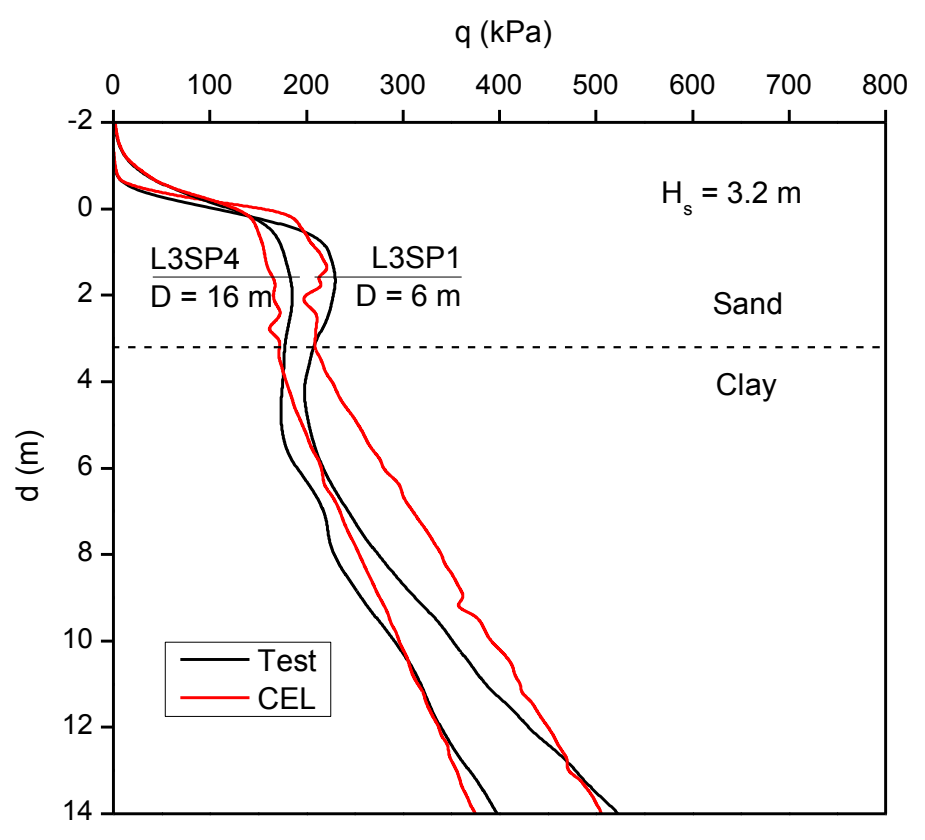

(c)

Fig. 9. Penetration resistance profiles from centrifuge tests and CEL analyses 


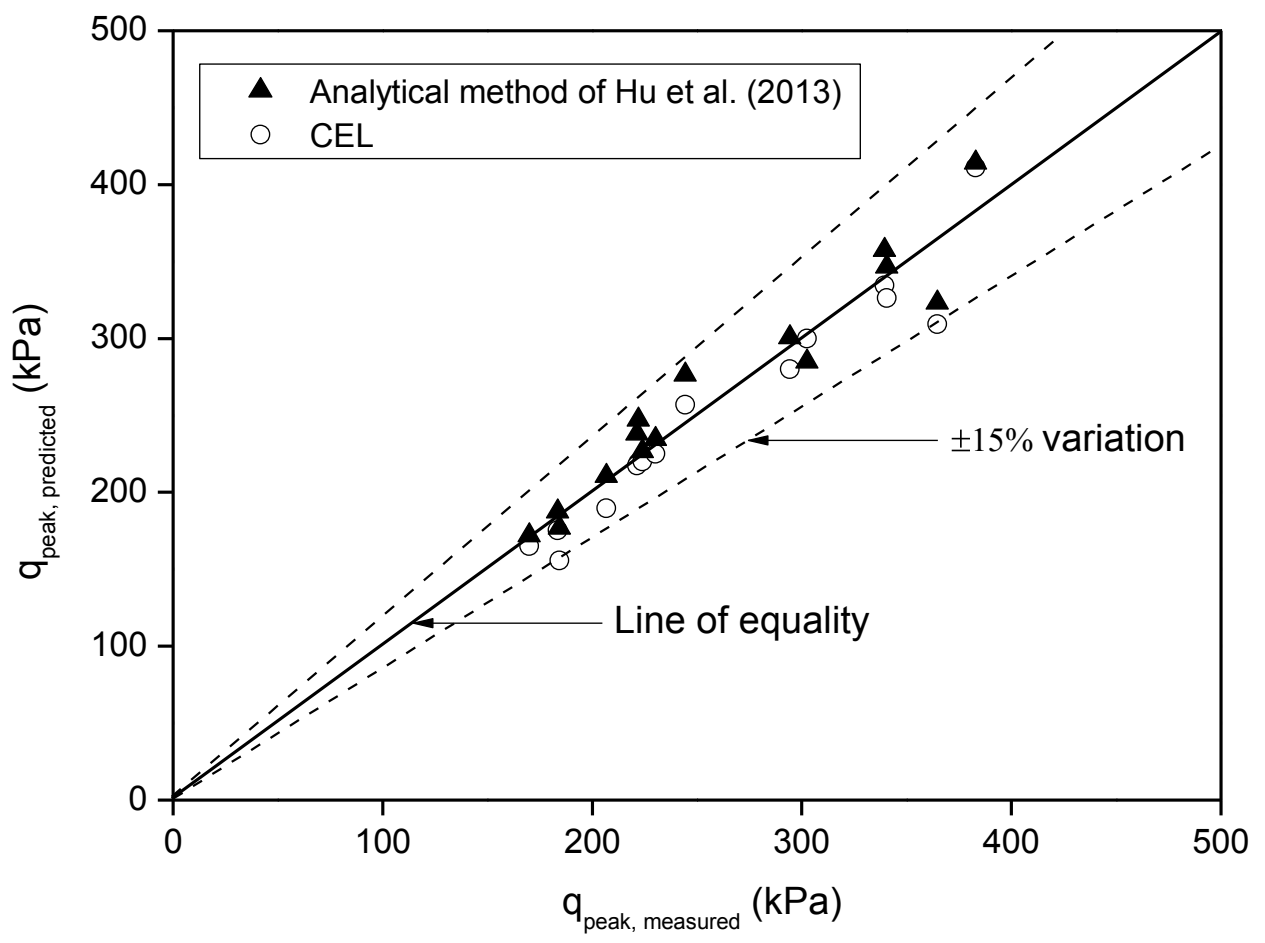

Fig. 10. Peak penetration resistances from centrifuge tests, CEL analyses and predicted formulations 

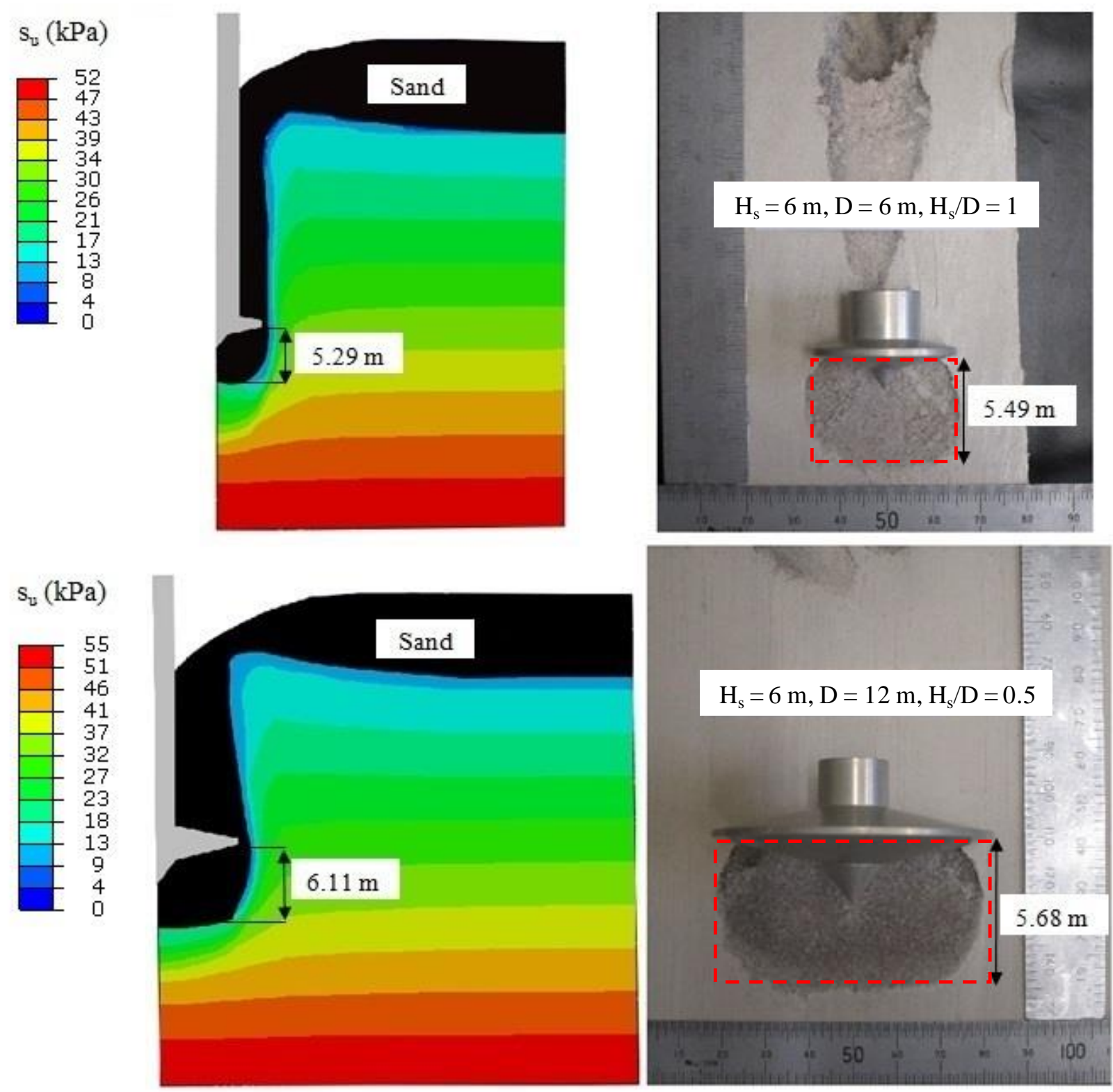

Fig. 11. Typical deformed sand and clay layers and sand plug heights 


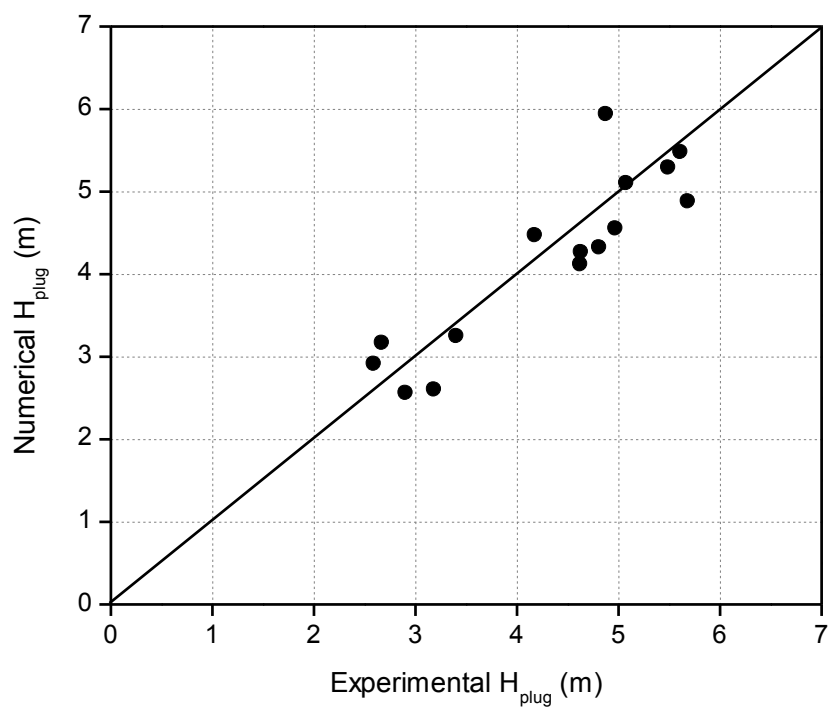

(a)

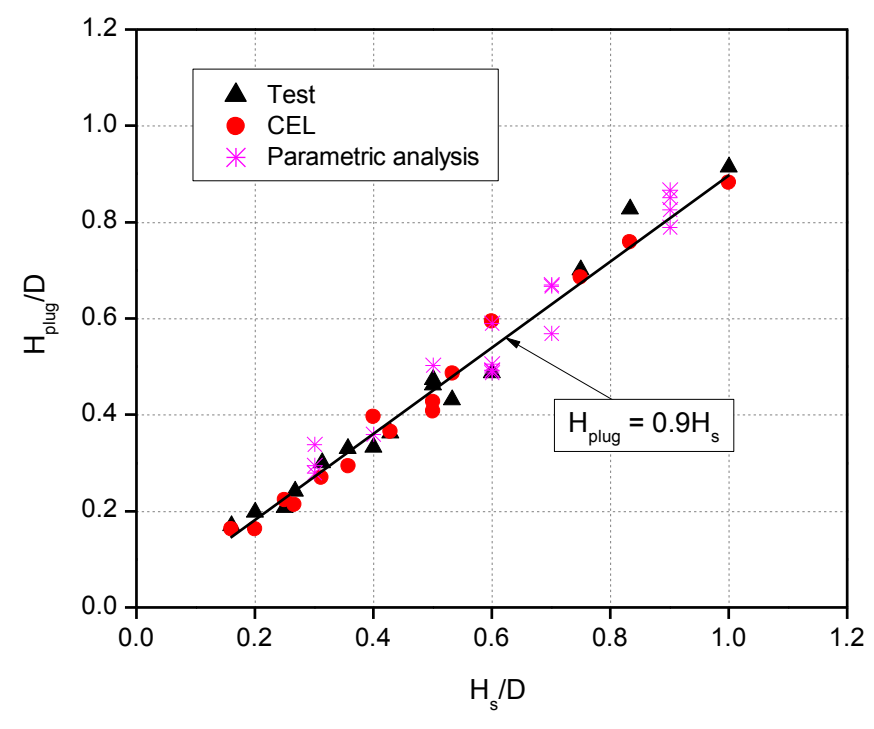

(b)

Fig. 12. (a) Comparison of calculated and experimental $\mathrm{H}_{\text {plug }}$ (b) Relationship between $\mathrm{H}_{\text {plug }}$ and $\mathrm{H}_{\mathrm{s}}$ 


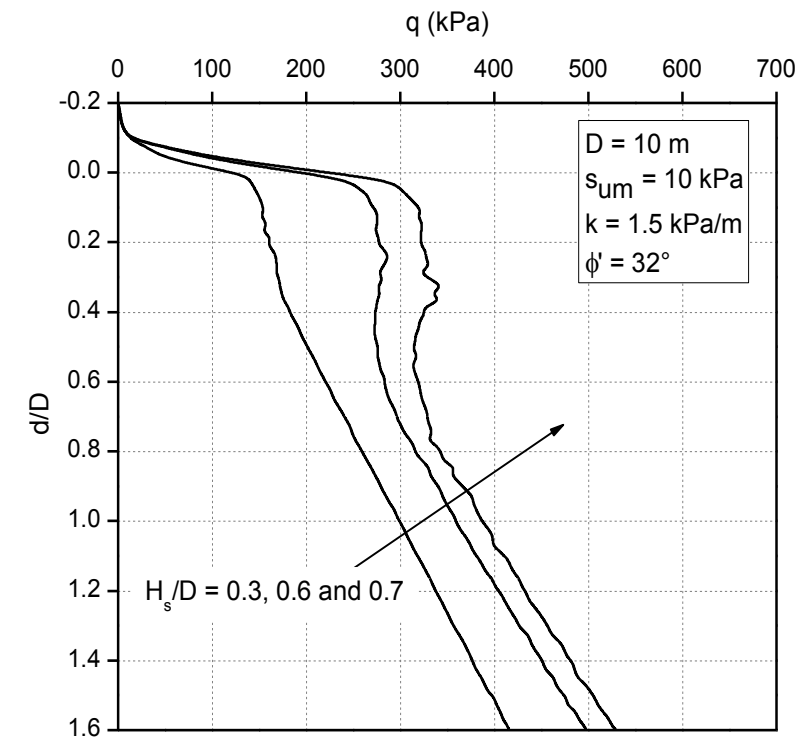

(a)

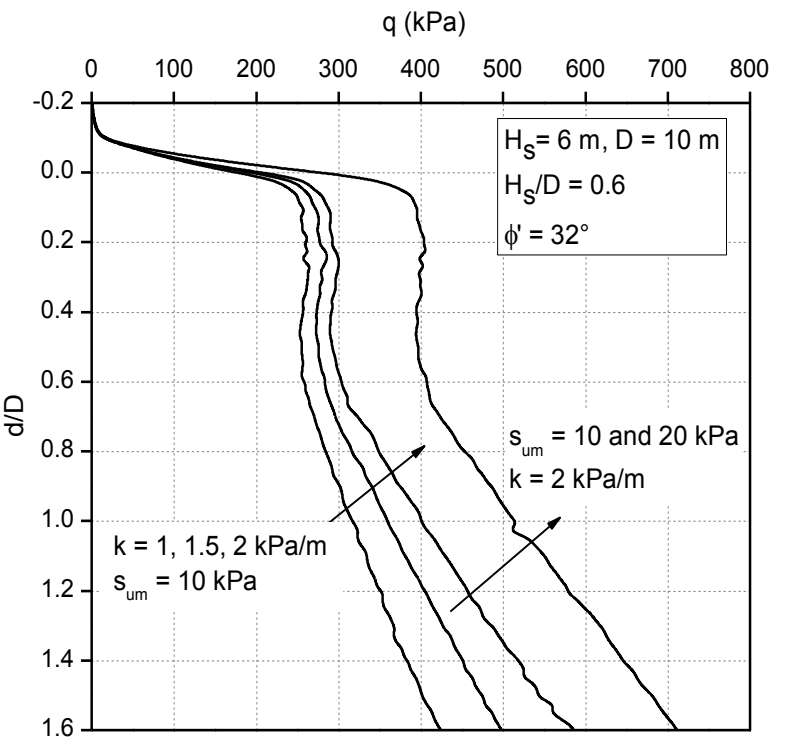

(b)

Fig. 13. Effects of $\mathrm{H}_{\mathrm{s}} / \mathrm{D}, \mathrm{k}$ and $\mathrm{s}_{\mathrm{um}}$ on penetration resistance profiles 


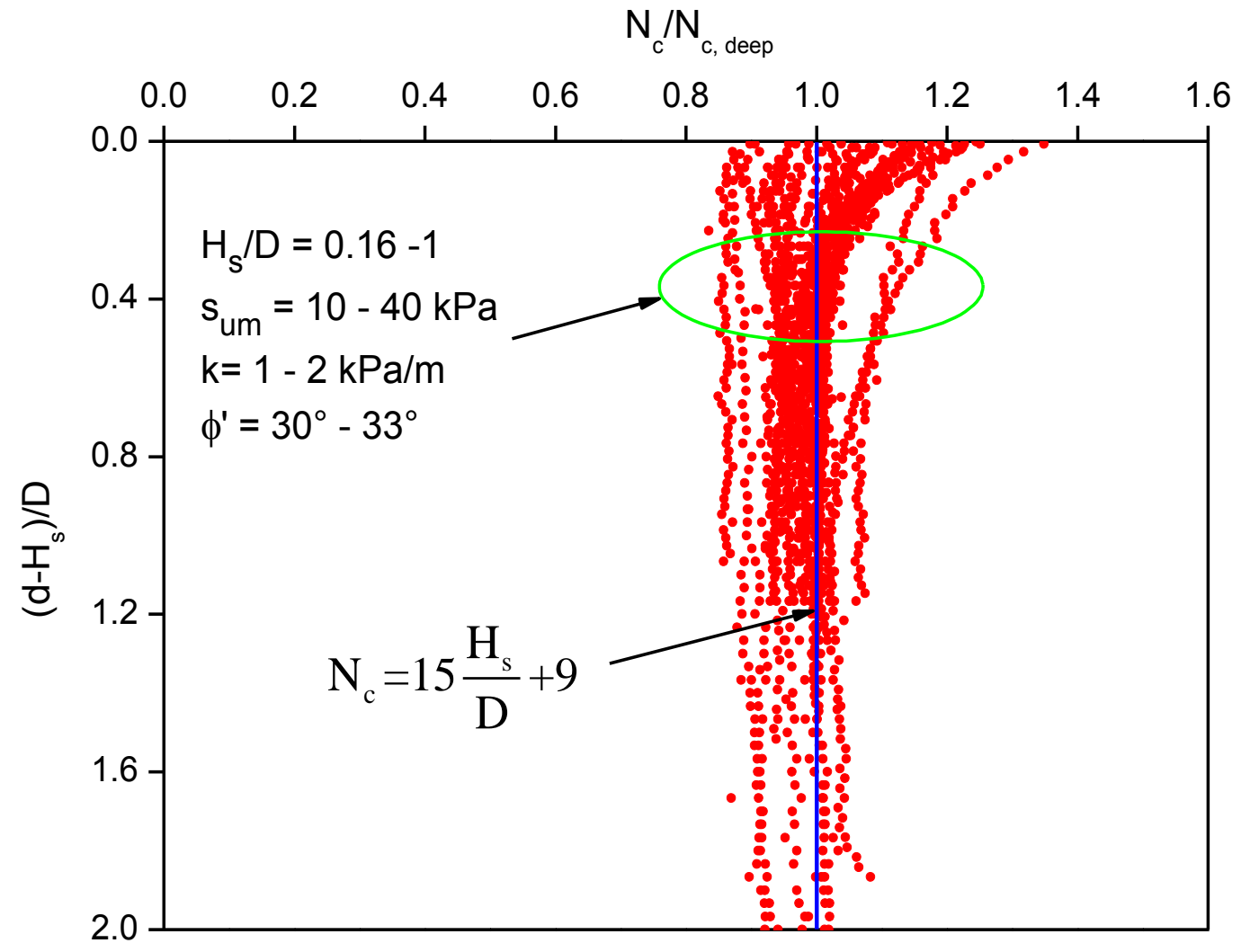

Fig.14. Bearing capacity factors from CEL simulations of centrifuge tests and parametric studies 


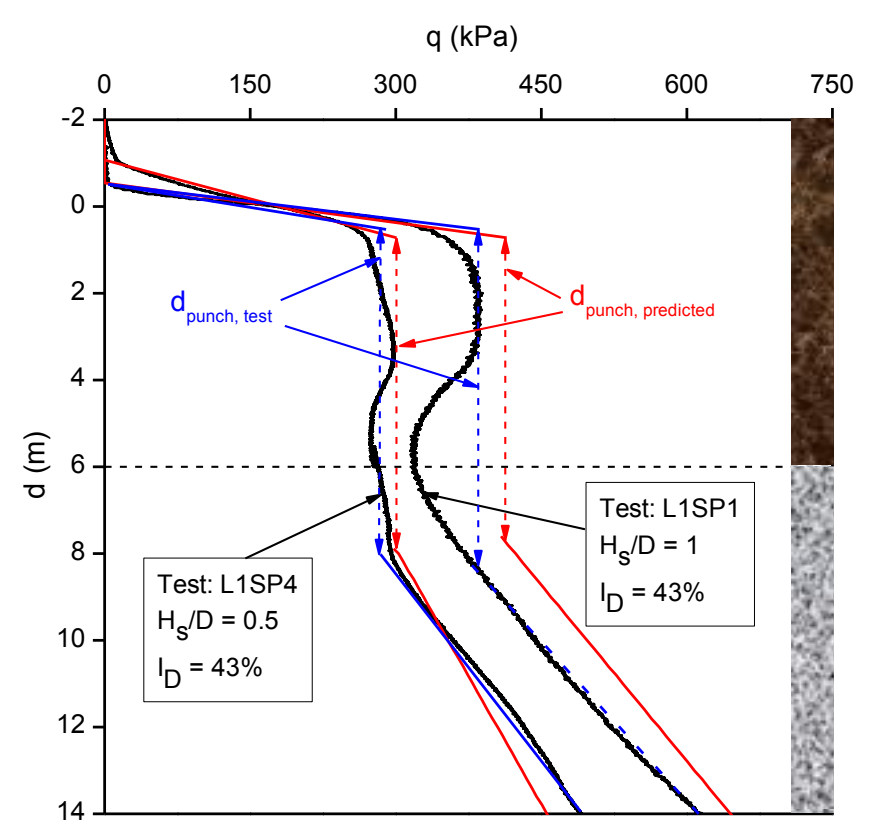

(a)

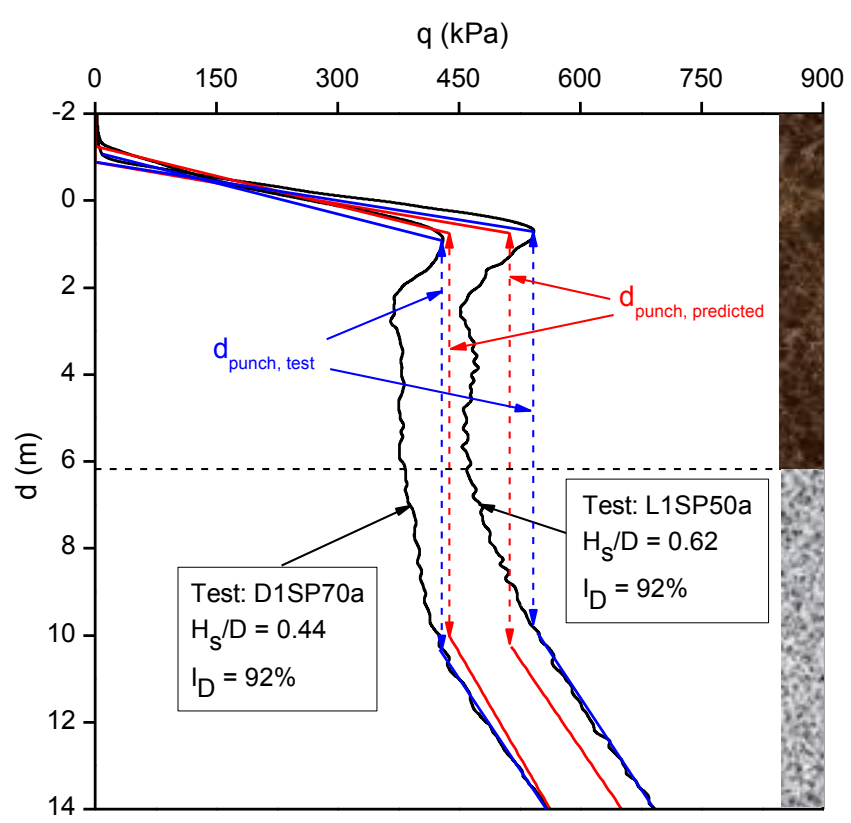

(b)

Fig. 15. Nomenclature of $d_{\text {punch, test }}$ and $d_{\text {punch, predicted }}$ for (a) medium dense and (b) dense sand tests 


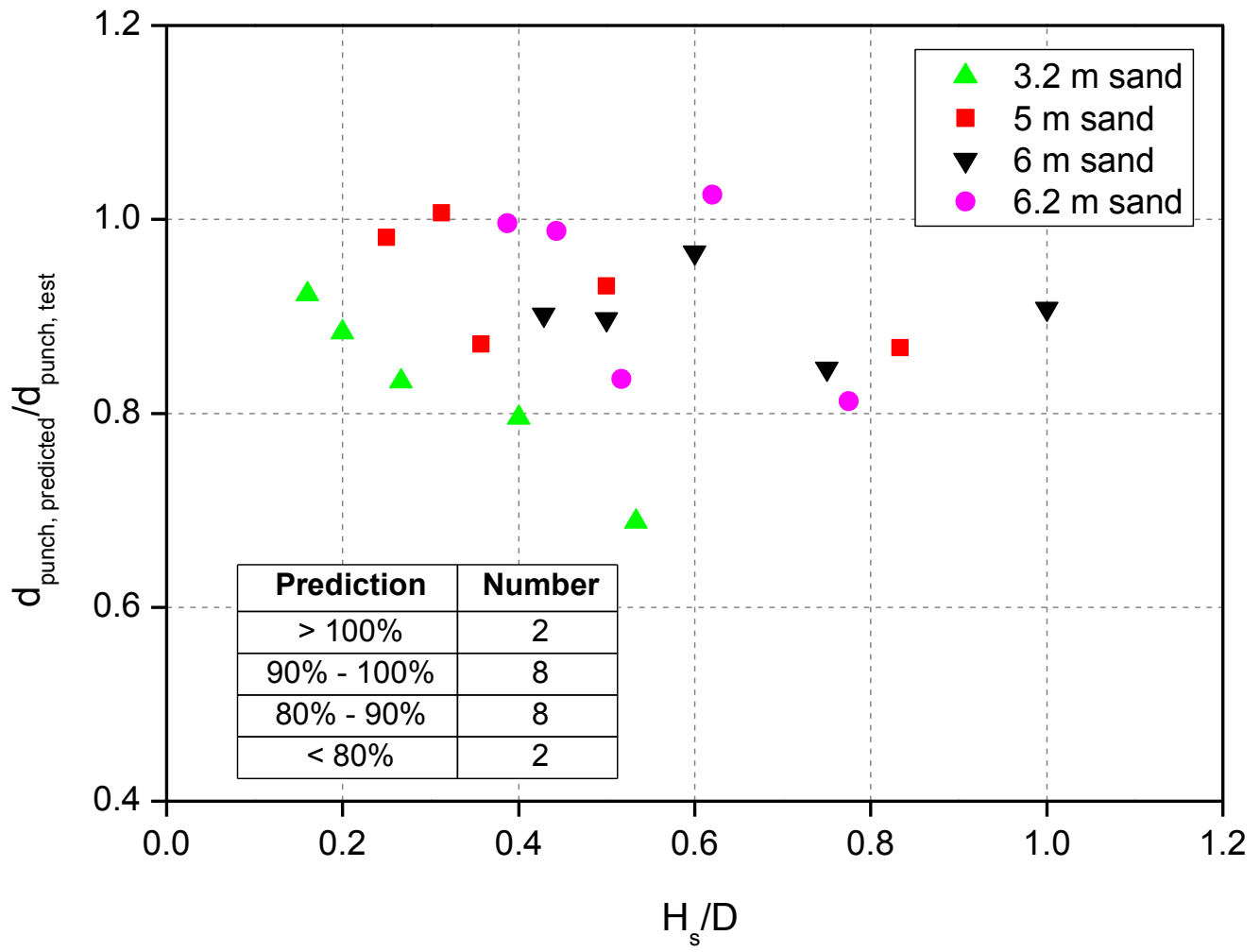

Fig. 16. Performance of the simplified prediction method by comparison of rapid penetration depth with that obtained from centrifuge tests 
Table 1. Prototype parameters and results of centrifuge and numerical tests of medium dense sand and dense sand overlying clay

\begin{tabular}{|c|c|c|c|c|c|c|c|c|c|c|c|c|c|c|}
\hline \multicolumn{8}{|c|}{ Experimental details } & \multicolumn{7}{|c|}{ Results } \\
\hline \multirow{2}{*}{ Test name } & \multicolumn{3}{|c|}{ Geometry } & \multicolumn{2}{|c|}{ Sand } & \multicolumn{2}{|c|}{ Clay } & \multicolumn{3}{|c|}{ Test } & \multicolumn{3}{|c|}{ CEL } & \multirow{2}{*}{$\begin{array}{r}\begin{array}{r}\text { Prediction } \\
\text { method }\end{array} \\
\mathrm{d}_{\text {punch }}(\mathrm{m})\end{array}$} \\
\hline & $\begin{array}{l}\mathrm{H}_{\mathrm{s}} \\
(\mathrm{m})\end{array}$ & $\begin{array}{c}\mathrm{D} \\
(\mathrm{m})\end{array}$ & $\mathrm{H}_{\mathrm{S}} / \mathrm{D}$ & $\mathrm{I}_{\mathrm{D}}(\%)$ & $\begin{array}{c}\gamma_{\mathrm{s}}^{\prime} \\
\left(\mathrm{kN} / \mathrm{m}^{3}\right)\end{array}$ & $\begin{array}{c}\mathrm{s}_{\mathrm{um}} \\
(\mathrm{kPa})\end{array}$ & $\begin{array}{c}\mathrm{k} \\
(\mathrm{kPa} / \mathrm{m})\end{array}$ & $\begin{array}{c}\mathrm{q}_{\text {peak }} \\
(\mathrm{kPa})\end{array}$ & $\begin{array}{c}\mathrm{H}_{\text {plug }} \\
\text { (m) }\end{array}$ & $\begin{array}{c}\mathrm{d}_{\text {punch }} \\
(\mathrm{m})\end{array}$ & $\begin{array}{c}\mathrm{q}_{\text {peak }} \\
(\mathrm{kPa})\end{array}$ & $\begin{array}{c}\mathrm{H}_{\text {plug }} \\
\text { (m) }\end{array}$ & $\mathrm{N}_{\mathrm{c} \text {, deep }}$ & \\
\hline L1SP1 & 6 & 6 & 1 & 43 & 9.96 & 12.96 & 1.54 & 382.95 & 5.49 & 7.80 & 410.96 & 5.29 & 23.06 & 7.08 \\
\hline L1SP2 & 6 & 8 & 0.75 & 43 & 9.96 & 12.96 & 1.54 & 339.53 & 5.60 & 8.40 & 334.44 & 5.48 & 19.05 & 7.11 \\
\hline L1SP3 & 6 & 10 & 0.6 & 43 & 9.96 & 12.96 & 1.54 & 364.78 & 4.88 & 7.40 & 309.12 & 5.94 & 18.25 & 7.15 \\
\hline L1SP4 & 6 & 12 & 0.5 & 43 & 9.96 & 12.96 & 1.54 & 294.41 & 5.68 & 8.00 & 279.95 & 4.88 & 15.83 & 7.18 \\
\hline L1SP5 & 6 & 14 & 0.43 & 43 & 9.96 & 12.96 & 1.54 & 302.53 & 5.07 & 8.00 & 300.00 & 5.11 & 15.20 & 7.21 \\
\hline L2SP1 & 5 & 6 & 0.83 & 43 & 9.96 & 12.36 & 1.54 & 340.57 & 4.97 & 6.80 & 326.32 & 4.55 & 21.40 & 5.90 \\
\hline L2SP2 & 5 & 10 & 0.5 & 43 & 9.96 & 12.36 & 1.54 & 244.44 & 4.63 & 6.40 & 256.76 & 4.27 & 16.57 & 5.96 \\
\hline L2SP3 & 5 & 14 & 0.36 & 43 & 9.96 & 12.36 & 1.54 & 222.11 & 4.62 & 7.00 & 219.06 & 4.12 & 14.16 & 6.10 \\
\hline L2SP4 & 5 & 16 & 0.31 & 43 & 9.96 & 12.36 & 1.54 & 221.33 & 4.80 & 6.20 & 217.28 & 4.33 & 13.08 & 6.24 \\
\hline L2SP5 & 5 & 20 & 0.25 & 43 & 9.96 & 12.36 & 1.54 & 223.99 & 4.17 & 6.40 & 220.00 & 4.48 & 12.72 & 6.28 \\
\hline L3SP1 & 3.2 & 6 & 0.53 & 43 & 9.96 & 11.01 & 1.55 & 230.22 & 2.59 & 5.60 & 225.13 & 2.92 & 16.62 & 3.86 \\
\hline L3SP2 & 3.2 & 8 & 0.4 & 43 & 9.96 & 11.01 & 1.55 & 206.75 & 2.66 & 4.90 & 189.67 & 3.17 & 15.27 & 3.90 \\
\hline L3SP3 & 3.2 & 12 & 0.27 & 43 & 9.96 & 11.01 & 1.55 & 183.61 & 2.90 & 5.00 & 175.33 & 2.57 & 13.10 & 4.16 \\
\hline L3SP4 & 3.2 & 16 & 0.2 & 43 & 9.96 & 11.01 & 1.55 & 184.32 & 3.18 & 4.70 & 155.56 & 2.61 & 12.11 & 4.15 \\
\hline L3SP5 & 3.2 & 20 & 0.16 & 43 & 9.96 & 11.01 & 1.55 & 169.92 & 3.40 & 4.60 & 165.00 & 3.25 & 11.45 & 4.25 \\
\hline
\end{tabular}




\begin{tabular}{|c|c|c|c|c|c|c|c|c|c|c|c|c|c|c|}
\hline D1SP40a* & 6.2 & 8 & 0.78 & 92 & 10.99 & 17.7 & 2 & 603 & N/A & 11.80 & N/A & N/A & N/A & 9.59 \\
\hline D1SP50a* & 6.2 & 10 & 0.62 & 92 & 10.99 & 17.7 & 2 & 534 & N/A & 9.20 & N/A & N/A & N/A & 9.43 \\
\hline D1SP60a* & 6.2 & 12 & 0.52 & 92 & 10.99 & 17.7 & 2 & 501 & N/A & 11.20 & N/A & N/A & N/A & 9.35 \\
\hline D1SP80a* & 6.2 & 16 & 0.39 & 92 & 10.99 & 17.7 & 2 & 456 & N/A & 9.25 & N/A & N/A & N/A & 9.21 \\
\hline
\end{tabular}

* Dense sand spudcan test from Lee (2009) 
Table 2. Summary of numerical parametric studies

\begin{tabular}{|c|c|c|c|c|c|c|c|c|}
\hline$\#$ & $\begin{array}{l}\mathrm{H}_{\mathrm{s}} \\
(\mathrm{m})\end{array}$ & $\mathrm{D}(\mathrm{m})$ & $\mathrm{H}_{\mathrm{s}} / \mathrm{D}$ & $\begin{array}{c}\mathrm{s}_{\mathrm{um}} \\
(\mathrm{kPa})\end{array}$ & $\begin{array}{c}\mathrm{k} \\
(\mathrm{kPa} / \mathrm{m})\end{array}$ & $\begin{array}{c}\varphi^{\prime} \\
\left(^{\circ}\right)\end{array}$ & $\begin{array}{c}\mathrm{H}_{\text {plug }} \\
(\mathrm{m})\end{array}$ & $\mathrm{N}_{\mathrm{c} \text {, deep }}$ \\
\hline 1 & 6 & 10 & 0.6 & 10 & 1 & 32 & 5.06 & 19.34 \\
\hline 2 & 6 & 10 & 0.6 & 10 & 1.5 & 32 & 4.94 & 18.35 \\
\hline 3 & 6 & 10 & 0.6 & 10 & 2 & 32 & 4.94 & 18.22 \\
\hline 4 & 6 & 10 & 0.6 & 20 & 1 & 32 & 4.88 & 17.70 \\
\hline 5 & 6 & 10 & 0.6 & 20 & 1.5 & 32 & 4.88 & 17.26 \\
\hline 6 & 6 & 10 & 0.6 & 20 & 2 & 32 & 5.90 & 16.81 \\
\hline 7 & 5.4 & 6 & 0.9 & 10 & 1.5 & 32 & 5.11 & 25.12 \\
\hline 8 & 5.4 & 6 & 0.9 & 20 & 1.5 & 32 & 4.96 & 20.09 \\
\hline 9 & 7 & 10 & 0.7 & 10 & 1.5 & 32 & 5.70 & 20.41 \\
\hline 10 & 7 & 10 & 0.7 & 20 & 1.5 & 32 & 6.67 & 18.96 \\
\hline 11 & 3 & 10 & 0.3 & 10 & 1.5 & 32 & 2.94 & 13.50 \\
\hline 12 & 3 & 10 & 0.3 & 10 & 1.5 & 30 & 2.80 & 12.56 \\
\hline 13 & 6 & 10 & 0.6 & 10 & 1.5 & 30 & 4.92 & 18.49 \\
\hline 14 & 5.4 & 6 & 0.9 & 10 & 1.5 & 30 & 5.20 & 20.80 \\
\hline 15 & 7 & 10 & 0.7 & 20 & 1.5 & 33 & 6.70 & 16.80 \\
\hline 16 & 7 & 14 & 0.5 & 40 & 1.5 & 32 & 6.04 & 14.97 \\
\hline 17 & 6.4 & 16 & 0.4 & 40 & 1.5 & 32 & 5.66 & 14.26 \\
\hline 18 & 6 & 20 & 0.3 & 30 & 1.5 & 32 & 5.77 & 14.55 \\
\hline
\end{tabular}

